\title{
Estudio sedimentológico de las bahías de San Ignacio y Navachiste en Sinaloa, México
}

\author{
S. Vergara-Méndez, S.M. Ortiz-Gallarza y M.L. García-Leal \\ Área de Tecnología de Control. Gerencia de Control Ambiental y Sustentabilidad. Subdirección de Protección \\ Ambiental. Instituto Mexicano del Petróleo. Universidad Autónoma Metropolitana \\ Email: sortiz@www.imp.mxysmogy@hotmail.com
}

(recibido: marzo de 1997; aceptado: septiembre de 2000)

\begin{abstract}
Resumen
Como aportación al conocimiento del sistema marino y la naturaleza de su fondo para la proliferación de especies como el camarón, en octubre de 1991 se realizó un estudio sedimentológico en la costa norte de Sinaloa, bahías de San Ignacio y Navachiste; y parcialmente, la plataforma continental. Fueron determinadas la granulometría y los contenidos de materia orgánica y carbonatos en 56 muestras de sedimentos, así como el conteo de partículas bajo el microscopio estereoscópico por el método de bandas en algunas de ellas. Los rasgos fisiográficos identificados en el área son antiguos cordones de playa, antiguas llanuras de inundación fluvial, playas, tómbolos y flechas remanentes de formaciones costeras. Los sedimentos lagunares se clasificaron en cuatro grupos texturales, los cuales varían desde arenas gruesas, hasta limos muy finos. El grupo predominante es el de las arenas finas a muy finas, las cuales comprenden el $78 \%$ de las muestras analizadas, distribuidas ampliamente en el substrato de las bahías y la plataforma continental. El contenido porcentual de carbonatos totales varía de 2 a $94 \%$, los valores modales fluctuaron entre 4 y 20\%, los mayores porcentajes se obtuvieron dentro de la bahía Navachiste en los extremos noroeste (55\%) y noreste (94\%), respectivamente. Los valores menores de 2 a $7 \%$ corresponden en general a los sedimentos arenosos de la plataforma. Los sedimentos de las bahías San Ignacio y Navachiste, así como los de la plataforma, son de origen continental y han sido transportados hacia la cuenca de depósito principalmente por los ríos Fuerte y Sinaloa.
\end{abstract}

Desciptores: sedimentología, costa de Sinaloa, bahías y plataforma.

\section{Abstract}

In order to contribute to the knowledge on the marine system and the nature of its bottom for the proliferation of species such as shrimps and oysters, a sedimentological study at the northern coast of Sinaloa (San Ignacio and Navachiste Bays), as well as a partial study of the continental shelf, were performed in October 1991. The grain size distribution and the organic matter and carbonates content were determined in 56 sediment samples. In addition, a counting was made of the different sizes of particles under the stereoscopic microscope by the bands method in some of the samples. The physiographic features identified in the area include old beach bars, antique river flood plains, beaches, tombolos and hooks, remainders of coastal formations. The tidal sediments were classified into four textural groups varying from coarse sands, to very fine silts. The predominant group corresponds to fine to very fine sands, which represents $78 \%$ of the analyzed samples, widely distributed in the bays and continental shelf substrata. The percentual content of total carbonates varies from 2 to 94\%, and the modal values fluctuate between 4 and 20\%; the largest percentages were obtained inside the Navachiste Bay, at the northwest (55\%) and northeast (94\%) boundaries, respectively. The values smaller than 2 to $7 \%$ in general correspond to sandy sediments of the shelf. The sediments covering the San Ignacio and Navachiste Bays, as well as those of the platform, have a continental origin and have been transported to the settling basin principally by the Fuerte and Sinaloa rivers. 


\section{Introducción}

Debido a las necesidades de desarrollo del país y el difícil logro para obtener un mejor conocimiento de los mares territorial y patrimonial, así como de las lagunas litorales, bahías y estuarios respecto a los recursos que contienen y su conservación, se realizó este estudio sedimentológico marino en octubre de 1991 en el noroeste de Sinaloa, que comprende las bahías de San Ignacio y Navachiste y parte de la zona infralitoral de la plataforma continental.

Las áreas antes mencionadas son importantes en la producción de alimentos, con relación a las pesquerías. El conocimiento de la distribución de los sedimentos en las lagunas litorales y bahías, está asociado a la posibilidad de un mejor aprovechamiento de áreas óptimas para el cultivo de especies tales como: camarón, ostión, pata de mula, etc., ya que las larvas y juveniles de estos organismos se desarrollan mejor en sitios londe predominan los sedimentos limo-arcillosos con alto contenido de materia orgánica.

La realización de un estudio sedimentológico, implica el conocimiento del marco geológico de las zonas adyacentes de la orografía, la hidrología, el clima y los procesos físicoquímicos en las zonas receptoras de los sedimentos.

\section{Antecedentes}

Aparentemente, este es el primer trabajo sedimentológico efectuado en las bahías de San Ignacio y Navachiste; en general, este tipo de investigaciones en la costa norte de Sinaloa han sido escasas. Sin embargo, algunos autores han incidido sobre aspectos geológicos, biológicos, fisicoquímicos, geofísicos, climatológicos, etc., de entre los cuales, se mencionan los de mayor interés.

Curray (1961) describe los cambios del nivel del mar en el Cuaternario. Van (1964), realiza una interpretación sobre la distribución, transporte sedimentario, aporte y origen de los detritos, la influencia batimétrica, la morfología submarina y facies de plataforma, talud y cuencas oceánicas. Contreras y Campos (1988), describen el comportamiento sedimentológico de la terraza continental sureste (plataforma y talud) del golfo de California.

Entre las investigaciones sedimentológicas y geomorfológicas de los litorales y plataforma de diversas localidades de Sonora y Sinaloa, se encuentran las de Lecuanda (1967), quien trata aspectos sedimentológicos relacionados con sedimentos detríticos; y López (1986), quien se refiere a la descripción de las características morfológicas y sedimentológicas en la plataforma continental de Sinaloa.

Algunos estudios realizados en los sistemas lagunares, las bahías y los esteros corresponden a Phleger y Ayala (1969), acerca de la geología marina de las bahías de Topolobampo y Ohuira, así como del estero Lechuguilla;
Alba et al., (1979), con la distribución de tipos de sedimentos en la bahía de Puerto Viejo, Mazatlán y la dirección prevaleciente de depósito con base en atributos texturales, estructurales y mineralógicos; Ayala et al., (1980) describen las características texturales de los sedimentos y su distribución; asimismo, analizan los procesos que actúan sobre la sedimentación, tales como mareas, vientos y corrientes de litoral en Yavaros, Sonora. Otro estudio sobre la determinación de características geomorfológicas y sedimentológicas de las lagunas Agiabampo y de su región circundante es el de Ayala et al., (1990).

Con respecto al contenido de carbono orgánico, destacan los estudios de García (1989), relativos a la materia orgánica en los sedimentos de la plataforma sureste del golfo de California, relaciones ecológicas y granulométricas; Muhech (1990), explica la distribución granulométrica y contenido de carbono orgánico en sedimentos de las bahías de Ohuira, Topolobampo y Santa María, Sinaloa; Muhech (1991), habla sobre distribución granulométrica y contenido de carbono orgánico en los sedimentos del sistema lagunar Teacapan-Agua Brava, Sinaloa-Nayarit.

\section{Área de estudio}

El área de estudio fue el litoral noroccidental de la República Mexicana, porción norte de la costa de Sinaloa que comprende las bahías de San Ignacio y Navachiste y parte de la plataforma continental; entre los paralelos $2520^{\prime} \mathrm{y}$ $2534^{\prime}$ latitud Norte y los meridianos $10840^{\prime}$ y $10903^{\prime}$ longitud Oeste (Fig. 1a y 1b).

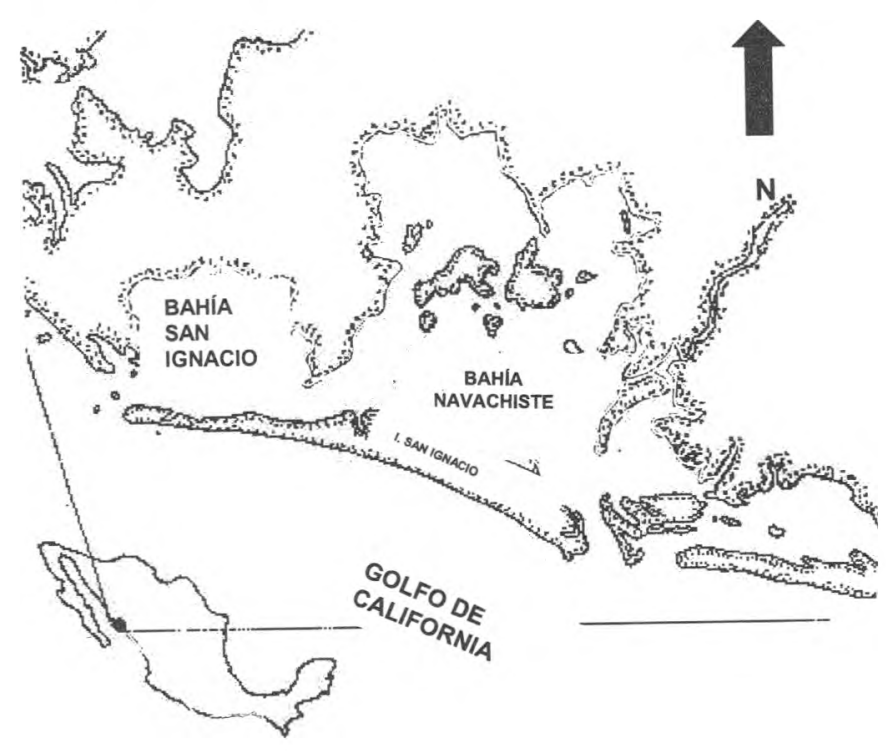

Figura la. Ubicación del área de estudio, bahias San Ignacio, Navachiste y plataforma continental interna. Localización en la República Méxicana 


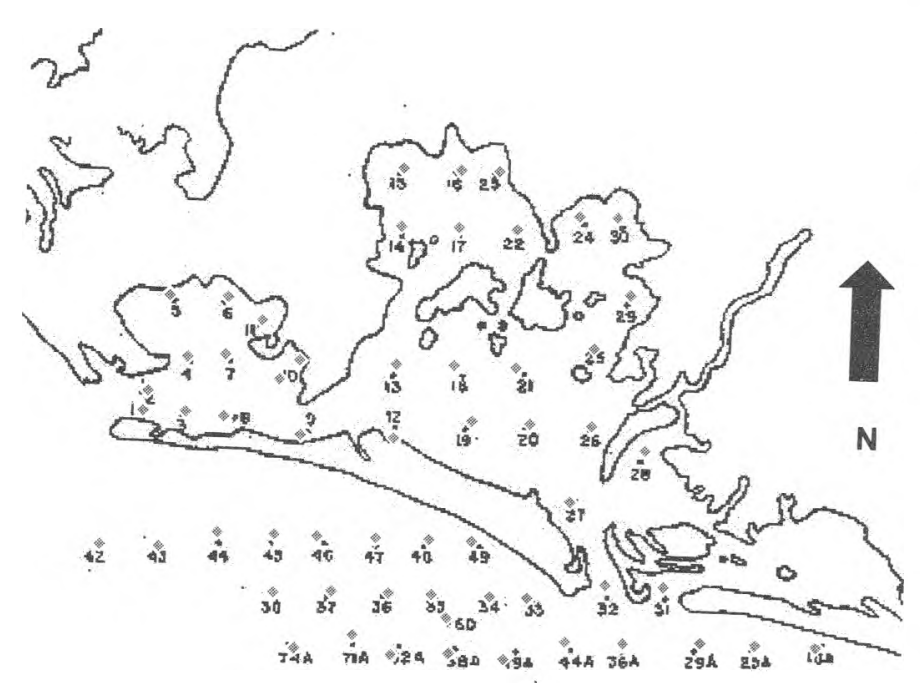

Figura 1b. Ubicación del área de estudio, bahias San Ignacio, Navachiste y plataforma continental interna. Ubicación geográfica de estaciones de muestreo. Octubre de 1991 (Vergara et al.,1991)

Moran (1984), en la descripción de la geología de Sonora y Sinaloa, menciona que la llanura costera del Pacífico se caracteriza por el desarrollo de una planicie constituida por la evolución de un sistema de deltas que han avanzado paulatinamente hacia el oeste. Entre los deltas que se incluyen en el área, se encuentran las desembocaduras de los ríos Fuerte y Sinaloa. Este mismo autor menciona que dichos deltas han cubierto prominencias rocosas, constituidas antiguamente como islas. La llanura costera, desde Mazatlán a los Mochis, forma un plano inclinado hacia el suroeste, razón por la cual en esta región el curso de los ríos es normal a la costa.

La bahía San Ignacio está semicerrada por la isla de San Ignacio; al oeste se comunica con el golfo de California y al este con la bahía Navachiste. Lankford (1977) la considera del tipo II-A, la cual se caracteriza por sedimentación terrígena diferencial, lagunas costeras asociadas con sistemas deltáicos fluviales producidos por sedimentación irregular o subsidencias de superficies que causan la compactación de los efectos de carga. Se han modificado durante los últimos $5 \mathrm{mil}$ años y se forman rápidamente barreras arenosas, que envuelven depresiones marginales o intradeltáicas muy someras (Fig. 2a).

La bahía Navachiste, semicerrada por la isla San Ignacio, se comunica al oeste con la bahía San Ignacio, al sur con el golfo de California y al sureste con la bahía Macapule; la boca del sector sureste se encuentra dividida en dos, por una isla arenosa denominada Vinorama, formada por la influencia de corrientes litorales y corrientes de marea, de entrada y salida a las lagunas. Lankford (1977), la ubica en el tipo III-A, plataforma de barrera interna, depresiones inundadas en los márgenes internos del borde continental, al cual rodean superficies terrígenas en sus márgenes internos y protegen del mar barreras arenosas producidas por corrientes y olas.

En la parte central de la bahía Navachiste se ubican las islas Nescoco, Tesobiare y hacia el norte de ésta, se ubica la isla el Aguacate; al sur de la misma, se localizan las islas el Metate y Guasayeye; existen otras muy pequeñas situadas en diferentes puntos.

Las bahías son someras, con una profundidad promedio de $0.70 \mathrm{~m}$ y un valor máximo de $10 \mathrm{~m}$ en la boca de la bahía Navachiste, el fondo de ambas es sensiblemente plano y sus rasgos geomorfológicos son: canales naturales, dos canales principales ubicados en las bocas de acceso al sistema de bahías, islas volcánicas, islas de barrera, tómbolos y flechas.

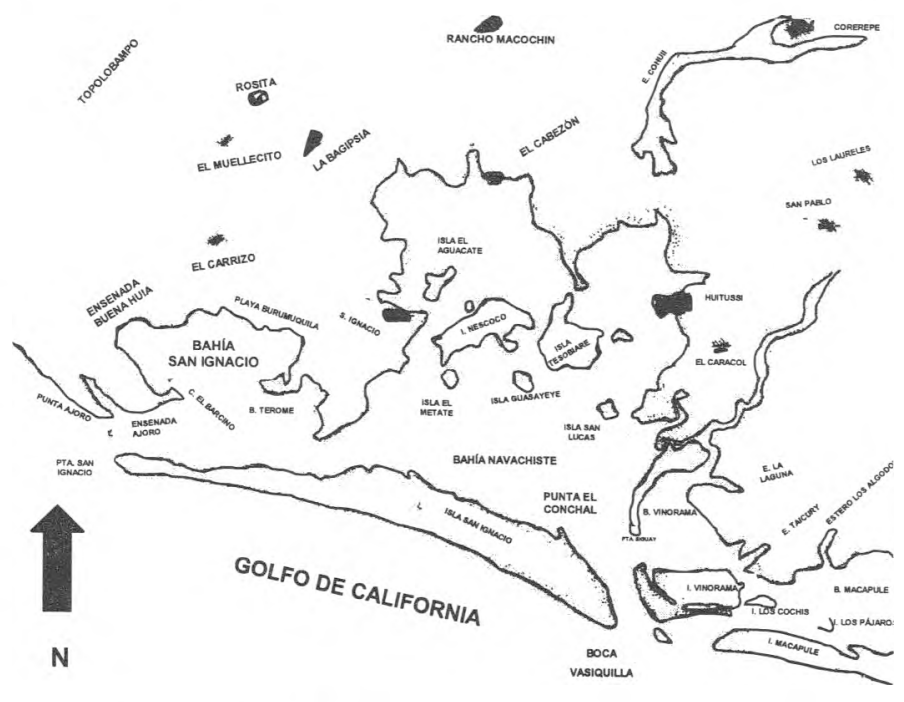

Figura 2a. Bahias San Ignacio, Navachiste y plataforma continental interna. Octubre de 1991.

Mapa toponímico (Vergara et al., 1991)

De acuerdo a la carta de climas de la República Mexicana (INEGI, 1984a) y al sistema de clasificación climática de Köppen, modificado por García (1973), en la región domina el clima tipo BW (h) w (e), caracterizado por un clima cálido, muy seco, con temperatura media anual sobre $22^{\circ}$ C y media del mes más frío de $18^{\circ} \mathrm{C}$, con lluvias en verano, la precipitación pluvial promedio es de $302 \mathrm{~mm}$ anuales, los meses lluviosos comprenden de julio a octubre, el porcentaje de lluvia invernal varía de 5 a $10.2 \%$ del total anual y la oscilación térmica entre 7 y $14^{\circ} \mathrm{C}$.

En términos generales, la red hidrográfica del área pertenece a la vertiente occidental y se ubica dentro de la región hidrológica 10 (R. H. 10, SARH, 1975). Todas sus corrientes se generan en la vertiente oeste de la Sierra Madre Occidental, o en sus estribaciones. Abarca una 
superficie aproximada de $103,212 \mathrm{~km}^{2}$. Las corrientes fluviales principales que tienen mayor influencia en el área, son los ríos Fuerte y Sinaloa. A continuación, se mencionan algunos aspectos importantes de éstos.

La cuenca del río Fuerte es la más importante de la R. H. 10, tanto por su extensión, como por los escurrimientos generados y las obras realizadas en ella. Abarca un área total de $35,590 \mathrm{~km}^{2}$ hasta San Blas, comprende aproximadamente $5,919 \mathrm{~km}^{2}$ en Sinaloa. Nace en las estribaciones de la Sierra Madre Occidental. En el estado de Sinaloa recibe como afluente al río Choix, a la altura de la población Agua Caliente de Lanfar. Descarga sus aguas en la presa Miguel Hidalgo y pasa por la población del Fuerte, recibiendo descargas de dicha población. Algunos afluentes son el arroyo Barotín y antes de pasar por San Blas, recibe la última aportación de importancia: el arroyo Sivajahui, por la márgen izquierda. Existen numerosos canales y cauces no descritos, ajenos a la cuenca, así como numerosas obras hidráulicas, caminos, etc., que complican la hidrografía y únicamente permiten identificar el curso del río.

El río Sinaloa nace en el cerro Mohinora, perteneciente a la Sierra Madre Occidental en el estado de Chihuahua. Se conoce en sus origenes como río Petatlán. Sigue una trayectoria de este a oeste, penetra al estado de Sinaloa donde sigue con rumbo general noroeste y después suroeste. Recibe la aportación de varios arroyos, entre los que se mencionan los Molinos, San José de Gracia y el río las Tahonas, pasando por las poblaciones de Bacubirito y de Sinaloa de Leyva. Ya en la zona baja recibe la confluencia, por la márgen derecha, del arroyo Cabrera y del arroyo Ocoroni y, finalmente desemboca en el golfo de California.

En el sistema de bahías, el intercambio de agua con el golfo de California es considerable, ya que la proporción de intercambio de agua y las velocidades de flujo y reflujo de las mareas, están en relación al tamaño, forma, número y amplitud de las bocas; a mayor velocidad de las corrientes, los canales tienden a ser más profundos y a incrementar la amplitud de las bocas, favoreciendo la migración o la erosión de los canales naturales de marea (Contreras, 1985).

La zona de estudio tiene cuatro diferentes tipos de suelos, todos ellos referidos a las islas, islotes, zonas de marismas y planicies costeras que rodean el área. Se consideró la descripción de la carta geológica del INEGI (1984b), ya que además de contener los tipos de suelos, proporciona una información muy provechosa acerca de los ambientes sedimentarios subaéreos, los cuales se describen enseguida:

\section{Ambiente litoral}

Constituido por arena suelta de grano fino, depositada por los movimientos de intermareas (olas, mareas y corrientes litorales); sus componentes principales son: cuarzo, feldespatos, fragmentos de conchas, rocas volcánicas y manganeso. Se localizan por grupos de alineaciones paralelas que forman barras, flechas, tómbolos y playas; atestiguan indicios de antiguas líneas de costa y regresión marina del Reciente, en algunos lugares está cubierto por dunas activas.

\section{Ambiente lagunar}

Está constituido por arcilla limosa expansiva de poco espesor, sobreyace a arena fina; sufre contaminación salina debido a la invasión intermitente del mar sobre el continente. Su morfología es de planicie y se encuentra a lo largo de la línea de costa.

\section{Ambiente eólico}

Este material arenoso ha sido transportado y depositado por el embate del viento cerca de la costa, cordones de dunas asimétricos, algunas con alturas hasta de $30 \mathrm{~m}$. Las dunas cuyos componentes principales son: cuarzo, feldespato, escasos fragmentos finos de roca volcánica y conchas, son de grano fino de color amarillo claro, sin consolidar y con estratificación cruzada.

\section{Ambiente aluvial}

Está compuesto por grava, arena, limo y arcilla no consolidada, su granulometría varía de material grueso al pie de la sierra, a fino en los valles y en la costa. Se originó por los depósitos de material detrítico que generaron los ríos Fuerte y Sinaloa al unir sus deltas en la región de la actual bahía de Topolobampo; estos materiales rodearon a prominencias rocosas que formaban antiguas islas.

En el área se presentan tres unidades geomorfológicas:

a) La primera unidad se formó por movimientos tectónicos e intrusiones ígneas que plegaron y fracturaron rocas metamórficas, sedimentarias y volcánicas, cuya edad varía del Paleozoico Superior al Terciario Medio. Estas montañas se encuentran disectadas por angostos y profundos cañones con orientación preferencial noreste-suroeste.

b) La segunda unidad esta constituida por derrames y emisiones de material ígneo extrusivo de composición ácida, intermedia y básica, que tuvieron su origen durante los eventos que conformaron la Sierra Madre Occidental y la apertura del golfo de California, en un período que va del Terciario Medio al Cuaternario. Su relieve es de picachos y mesetas irregulares disectadas por angostos cañones, rellenados en su base por material clástico continental del Reciente. La Sierra Madre Occidental por su magnitud y 
extensión representa el principal elemento geomorfológico, donde destaca la secuencia volcánica más extensa y espectacular de México que comprende las ignimbritas, rocas volcánicas ricas en sílice, originadas durante eventos explosivos muy fuertes, que se caracterizan por contener fragmentos aplanados de vidrio.

c) La tercera unidad corresponde a los deltas desarrollados por los ríos Fuerte y Sinaloa, con acumulaciones de material detrítico del Reciente que rodean prominencias que correspondieron a islas antiguas. En la franja costera hay estuarios y depósitos arenosos que han sido depositados por las corrientes litorales, mareas, viento y oleaje, dando lugar a la formación de dunas, barreras, islas de barrera y tómbolos, debido a la acumulación sedimentaria. Estos materiales corresponden a antiguas líneas de costa y sugieren una regresión marina junto con una progradación de la costa.

\section{Andesita. Brecha volcánica intermedia}

La constituyen derrames y material piroclástico de composición intermedia, localizados alrededor de la bahía San Ignacio, formando la Sierra de Navachiste. La andesita subyace y está intercalada con brecha volcánica intermedia, está fracturada intensamente; en algunos lugares tiene alteración hidrotermal. Aflora en la ribera norte de la bahía Navachiste formada por el cerro Cabezón, y en la parte central de la misma bahía formando las islas Nescoco, Tesobiare y otras de menor tamaño.

\section{Basalto. Brecha volcánica básica}

La integra una alternancia de lavas y material piroclástico de composición básica. El basalto está compuesto por minerales de plagioclasa cálcica, olivino, hematita y magnetita, con matriz vítrea; su estructura es compacta y vesicular y está intensamente fracturada. Los afloramientos se localizan al noroeste y este de la bahía San Ignacio. Su expre. sión morfológica es de lomeríos y mesetas, éstas en algunos flancos presentan pendientes verticales.

\section{Aluvión}

Unidad de depósitos de arena, grava, limo y arcilla sin consolidar, que han sido depositados por los ríos y arroyos del área, dando así lugar a una gran planicie costera que rodea el área (Malpica et al., 1975) (Fig.3a).

\section{Material y métodos}

Se diseñó una red de estaciones de trabajo en la que estuviera contemplada la mayor parte del área, con una distancia aproximada de dos millas entre estación y estación. Los muestreos se efectuaron a bordo de una lancha con motor fuera de borda, se colectaron muestras de sedimentos en 56 estaciones. La recuperación se llevó a cabo con una draga Smith McIntyre con capacidad de 10.5 litros, sujeta a un cabo de nylon de $3 / 4$ de pulgada de diámetro y $25 \mathrm{~m}$ de longitud. La profundidad de recuperación del sedimento fluctuó entre 1 y $10 \mathrm{~m}$ en las bahías y entre 3 y $20 \mathrm{~m}$ en la plataforma continental (Fig. 2b; tabla 1). Del material obtenido con la draga, fue tomado $1 \mathrm{~kg}$ del sedimento más superficial y se guardó en bolsas de polietileno con los datos de campo necesarios.

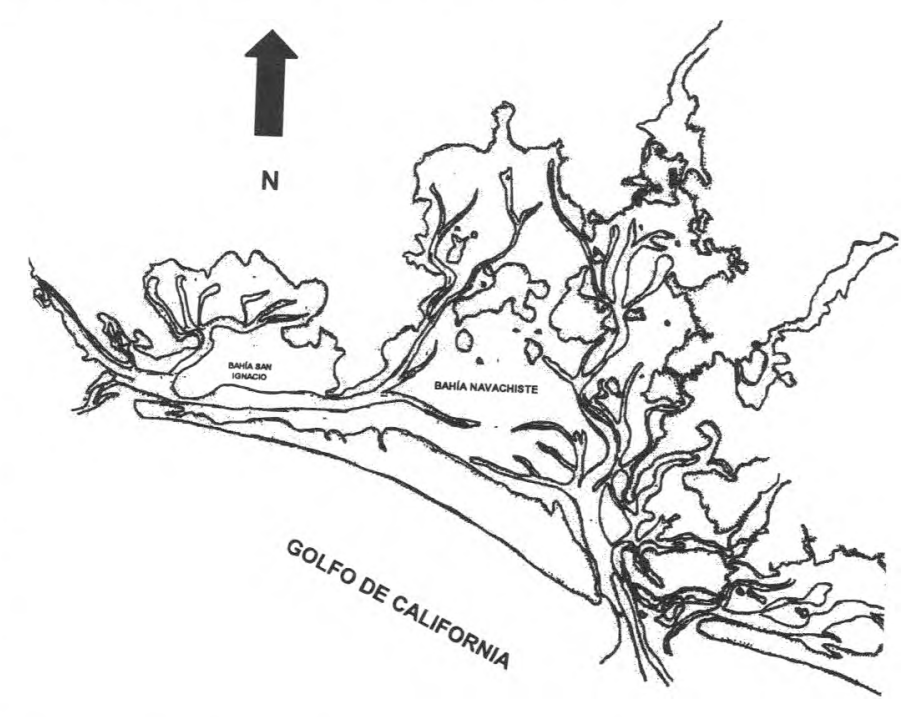

Figura 2b. Bahias San Ignacio, Navachiste y plataforma continental interna. Octubre de 1991.

Mapa batimétrico (Vergara et al., 1991)

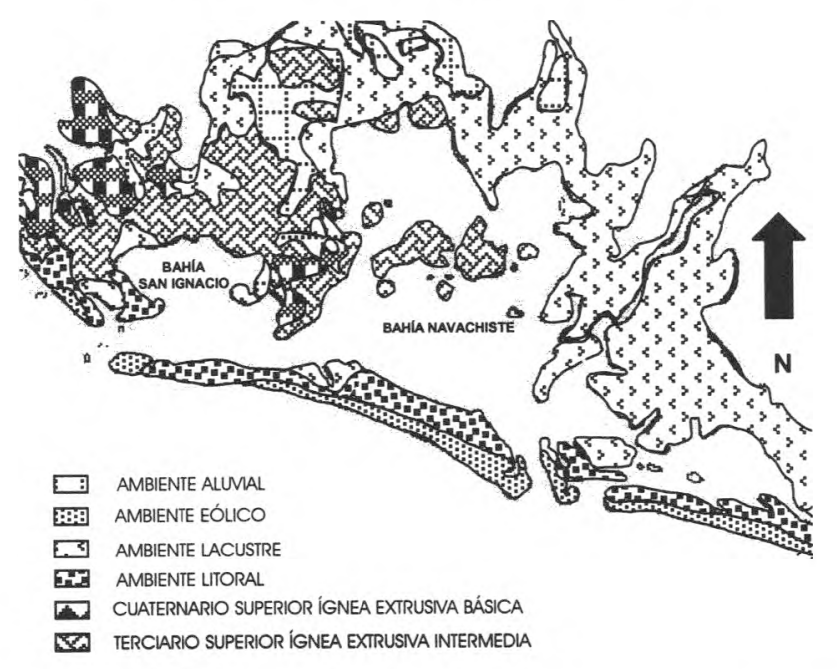

Figura 3a. Bahias San Ignacio, Navachiste y plataforma continental interna. Octubre de 1991.

Geología y ambientes sedimentarios subaéreos (SPP, 1984) 
DOI: http://dx.doi.org/10.22201/fi.25940732e.2001.02n1.002

Tabla 1. Batimetría del área de estudio, octubre de 1991

\begin{tabular}{|c|c|c|}
\hline & No. de Estación & Batimetría (m) \\
\hline $\mathrm{S}$ & 1 & 7.0 \\
\hline A & 2 & 6.0 \\
\hline \multirow[t]{2}{*}{$\mathrm{N}$} & 3 & 1.0 \\
\hline & 4 & 0.80 \\
\hline I & 5 & 0.30 \\
\hline G & 6 & 0.25 \\
\hline $\mathrm{N}$ & 7 & 0.30 \\
\hline A & 8 & 1.25 \\
\hline C & 9 & 1.05 \\
\hline I & 10 & 0.40 \\
\hline \multirow[t]{7}{*}{0} & 11 & 0.30 \\
\hline & 12 & 1.70 \\
\hline & 13 & 0.90 \\
\hline & 15 & 0.60 \\
\hline & 16 & 0.25 \\
\hline & 17 & 0.30 \\
\hline & 18 & 0.38 \\
\hline $\mathrm{N}$ & 19 & 0.40 \\
\hline A & 20 & 3.60 \\
\hline V & 21 & 0.90 \\
\hline A & 22 & 1.15 \\
\hline C & 23 & 0.70 \\
\hline $\mathrm{H}$ & 24 & 0.35 \\
\hline I & 25 & 0.30 \\
\hline $\mathrm{S}$ & 26 & 0.23 \\
\hline $\mathrm{T}$ & 27 & 0.47 \\
\hline \multirow[t]{12}{*}{$\mathrm{E}$} & 28 & 4.80 \\
\hline & 29 & 2.30 \\
\hline & 30 & 4.00 \\
\hline & 31 & 3.10 \\
\hline & 32 & 0.40 \\
\hline & $18 \mathrm{~A}$ & 6.70 \\
\hline & $25 \mathrm{~A}$ & 0.35 \\
\hline & $29 \mathrm{~A}$ & 8.00 \\
\hline & 33 & 10.00 \\
\hline & 34 & 7.20 \\
\hline & 35 & 6.80 \\
\hline & 36 & 7.40 \\
\hline $\mathrm{P}$ & $36 \mathrm{~A}$ & 9.70 \\
\hline $\mathrm{L}$ & 37 & 13.40 \\
\hline A & 38 & 12.60 \\
\hline$T$ & 42 & 13.40 \\
\hline A & 43 & 14.00 \\
\hline $\mathrm{F}$ & 44 & 13.70 \\
\hline $\mathrm{O}$ & $44 \mathrm{~A}$ & 12.40 \\
\hline $\mathrm{R}$ & 45 & 9.80 \\
\hline M & 46 & 7.20 \\
\hline \multirow[t]{9}{*}{ A } & 47 & 7.80 \\
\hline & 48 & 5.40 \\
\hline & 49 & 4.20 \\
\hline & $49 \mathrm{~A}$ & 3.70 \\
\hline & $58 \mathrm{~A}$ & 7.40 \\
\hline & $60 \mathrm{~A}$ & 17.20 \\
\hline & $62 \mathrm{~A}$ & 16.30 \\
\hline & $71 \mathrm{~A}$ & 18.40 \\
\hline & $74 \mathrm{~A}$ & 19.20 \\
\hline
\end{tabular}

Con la finalidad de conocer las características texturales de los sedimentos depositados tanto en el fondo de las bahías, como en la plataforma continental de los 56 sitios mues. treados, 11 corresponden a la bahía San Ignacio, 20 a la bahía de Navachiste y las 25 restantes se ubicaron en la plataforma (Fig. 1).

Para las determinaciones de materia orgánica se consideró una submuestra de material recuperado en la draga, de unos $5 \mathrm{~g}$ aproximadamente, con una cuchara no metálica, inmediatamente se secaron cada una de las muestras en una estufa (a 40-60ㅇ) , con la finalidad de evitar cualquier alteración de la materia orgánica contenida en el sedimento.

Antes de iniciar el análisis granulométrico, a las muestras de sedimento se les aplicó un pretratamiento, con la finalidad de evitar la floculación de las partículas sedimentarias, para tal efecto se utilizó el método de digestión con peróxido de hidrógeno al 30\%, citado por Folk (1969).

El análisis granulométrico se dividió en dos etapas: Tratamiento de la fracción fina y tratamiento de la fracción gruesa:

a) Tratamiento de la fracción gruesa. Mediante este tratamiento el tamaño de las partículas es medido por su velocidad de asentamiento en un medio fluido, de acuerdo a la Ley de Stokes (1851), en donde la velocidad de sedimentación de las partículas, es independiente de la visco. sidad del fluido y es directamente proporcional a lá raíz cuadrada del diámetro de la partícula (Krumbein, 1932; Krumbein y Sloss, 1969).

b) Tratamiento de la fracción fina. Para este estudio se empleó el análisis del sédimento por medio del tubo de sedimentación de Emery (1938), que permite evaluar el tamaño de las partículas comprendido de $0 \varphi$ a $4 \varphi$ en arenas. La partícula al asentarse en agua, es atraída hacia abajo con una fuerza que depende del volumen de la partícula, de la aceleración de la gravedad y de la diferencia entre la densidad de la partícula y la del fluido (Poole, 1957).

Donde:

$$
\varphi=-\log _{2}(d)
$$

$\varphi=$ unidades $p h i$

$\mathrm{d}=$ diámetro de las partículas en $\mathrm{mm}$

Para el análisis de carbono orgánico, las muestras fueron analizadas por el método propuesto por Walkley y Black (1934), modificado por Jackson (1958), el cual se basa en la oxidación de la materia orgánica por la acción de dicromato de potasio y ácido sulfúrico, donde el exceso de reactivo oxidante se evalúa por titulación con una sal ferrosa estándar, en esta ocasión sulfato ferroso amoniacal hexahidratado. Los datos resultantes fueron tratados aritméticamente, mediante la fórmula establecida en el mismo método, dando como resultado el contenido de carbono orgánico: 

$\% \mathrm{C} . \mathrm{O}=10(1-\mathrm{T} / \mathrm{S}) 1.0 \mathrm{~N}(0.003)(100 / \mathrm{W})$

Donde:

$\mathrm{T}=m l$ de la solución de sulfato ferroso amoniacal gastados en la titulación de la muestra.

$S=m l$ de la solución de sulfato ferroso amoniacal gastado en la titulación del blanco estándar.

$0.003-12 / 4000=$ peso $\mathrm{mcg}$ del carbono.

$1.0 \mathrm{~N}=$ normalidad del dicromato de potasio.

$10=$ volumen del dicromato de potasio en $\mathrm{ml}$.

$\mathrm{W}=$ peso de la muestra en $g$.

Con respecto a la determinación de carbonatos, se efectuó simplemente por pérdida de peso después de un tratamiento con $\mathrm{HCl}$ diluido, calentando la muestra de 1 a 5 minutos en los casos necesarios, a fin de fraccionar los carbonatos menos solubles. El método detallado puede consultarse en Grant (1971).

Para la realización del análisis mineralógico se pesaron $5 \mathrm{~g}$ de sedimento de cada muestra, una vez pesada la muestra se cuarteó y cribó en los tamices con abertura de malla 3 y $3.5 \varnothing$; el sedimento que quedó retenido en el tamiz $3.5 \varnothing$ fue vaciado en cápsulas de porcelana y se le practicó el método descrito por Gabriel y Cox (1929). La tinción de feldespatos es recomendable para separar muestras de cuarzo y feldespatos. Para este estudio se identificaron 500 granos de cada una de las muestras, por el método de líneas o bandas de Carver (1971).

\section{Resultados}

En el área de estudio fue posible diferenciar las siguientes unidades (Fig. 3b), desde el punto de vista fisiográfico:

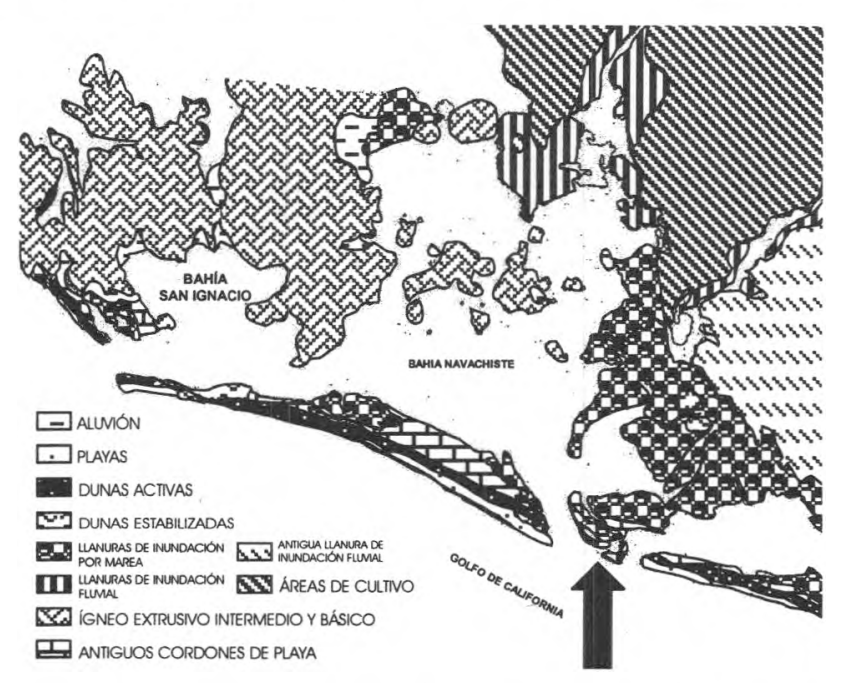

Figura 3b. Bahias San Ignacio, Navachiste y plataforma continental interna. Octubre de 1991. Mapa fisiográfico del área de estudio (Vergara et al.,1991)
1) Isla Macapule, formada por un cordón de dunas activas y un cordón de dunas estabilizadas por vegetación pionera. Hacia el extremo oriental se encuentra una llanura de inundación de mareas, constituida por sedimentos limo-arcillosos; se encontraron algunos manglares en los canales de la llanura.

2) El borde interior de la bahía Macapule está configurado por una llanura de inundación de intermareas, con un patrón de canales bien definido.

3) En la porción nororiental se encuentra un antiguo sistema de llanuras de inundación fluvial con meandros abandonados, probablemente éste sistema meándrico corresponde a un antiguo cauce del río Sinaloa, cuya migración ha ido hacia el sureste, hasta su actual desembocadura en el golfo de California.

4) También se presenta el estero el Colorado constituido por sedimentos finos de tipo limo-arcilloso.

5) La isla Vinorama está configurada por un cordón de dunas. Las formas terminales de la isla en punta de gancho, obedecen a las corrientes de marea (de entrada y salida del agua de la bahía).

6) Hay islas de origen volcánico en el interior de la bahía Navachiste.

7) Hacia la parte norte, cerca del poblado el Cabezón, se localiza una gran llanura de inundación fluvial, caracterizada por sedimentos areno limosos, presenta canales de intermarea y en algunas partes es posible observar zonas de evaporación.

8) La isla San Ignacio consta de una playa activa que da al golfo de California, un cordón de dunas activas y antiguos cordones de playa que evidencían el carácter progradante de la región y de la isla en particular. Su origen es similar al descrito por Curray et al., (1969), para las regiones de Nayarit y del sur de Sinaloa. En la parte interior de esta isla existen zonas de inundación en canales de intermarea y vegetación del tipo de manglar. Hacia ambos extremos de la isla se pueden observar barreras subaéreas tipo gancho.

9) Hacia la parte noroeste se encuentra la sierra de Navachiste, formada por rocas volcánicas intermedias y básicas, con pequeños depósitos aluviales en las partes bajas, provenientes de la erosión de las mismas rocas volcánicas.

10) En la parte oriental de la bahía San Ignacio, se presenta un cordón de dunas activas y un cordón de antiguas líneas de costa, rodeados por una llanura de inundación con 
canales de intermarea, en la parte oriental se encuentra un tómbolo, que une lo que fue una isla volcánica con el sistema de antiguos cordones litorales (Fig. 2).

Los sedimentos lagunares se clasifican en cuatro grupos texturales, los cuales varían desde arenas gruesas, medias y muy finas hasta los limos muy finos. El grupo predominante es el de las arenas finas a muy finas, las cuales comprenden el $78 \%$ de los sedimentos analizados; son muy abundantes en la plataforma y en la mayor parte de las bahías; han sido aportadas por el oleaje, las mareas y el viento, también son arenas cuarzofeldespáticas, cuyos granos de cuarzo varían de 55 a $87 \%$ y los feldespatos de 1 a $21 \%$.

Los fragmentos de roca son escasos, la mayoría ígneos, y se encuentran en la ribera norte de la isla San Ignacio y en la ribera noroeste de la bahía Navachiste, por lo que se deduce que la fuente de origen de tales fragmentos de roca son la Sierra Navachiste y las islas volcánicas.

Los datos cuantitativos del tamaño de las partículas sedimentarias, se obtuvieron con el propósito de clasificarlas, describir su distribución e interpretar aspectos del origen, transporte y ambiente sedimentario. Una de las características sobresaliente de los sedimentos, es su predominancia de arenas de grano fino a muy fino, con tamaño promedio $\mathrm{Mz}$ comprendido entre 2.15 y $2.74 \varphi$, que varían de muy bien clasificadas a mal clasificadas, el índice de clasificación, I o, varía de 0.29 a 1.73 , a excepción de las muestras 10,15 y 24 , cuya caracterización es muy mal clasificada con valores, I o: $2.48,3.28$ y $3.14 \varphi$, respectivamente, y de muy asimétricas hacia los tamaños finos, a muy asimétricas hacia los tamaños gruesos.

La posición de los sedimentos en el diagrama ternario propuesto por Shepard (1954), muestra la distribución de los grupos establecidos (Fig. 4a). La correlación entre el tamaño promedio y los índices de asimetría y de clasificación entre el tamaño promedio, así como los índices de asimetría y de clasificación, permitió identificar los siguientes cuatro grupos texturales (Fig. 5a) de acuerdo al método de Inman (1952) (Tabla 2; Fig. 3).

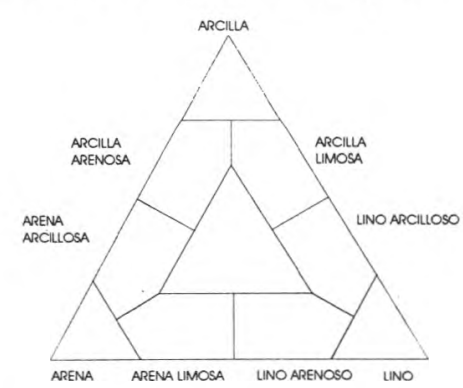

Figura 4a. Bahías San Ignacio, Navachiste y plataforma continental interna. Octubre de 1991.

Clasificación de grupos de sedimentos con base en Shepard (1954)

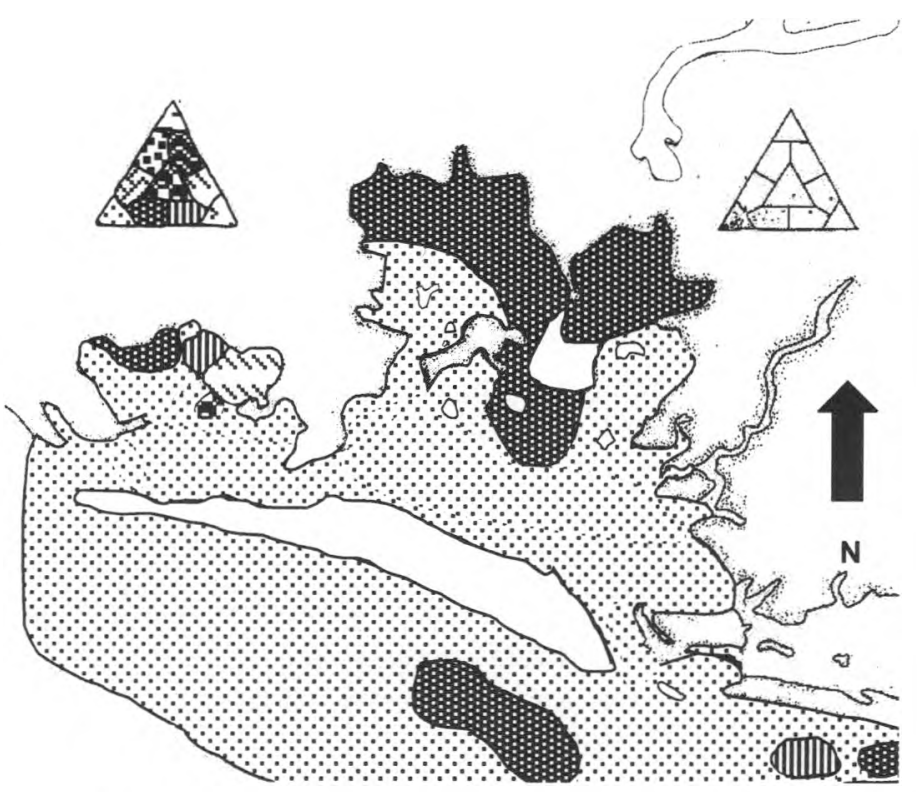

Figura $4 b$. Bahias San Ignacio, Navachiste y plataforma continental interna. Octubre de 1991.

Mapa de distribución de sedimentos tipo con base en Shepard (1954), (Vergara et al., 1991)

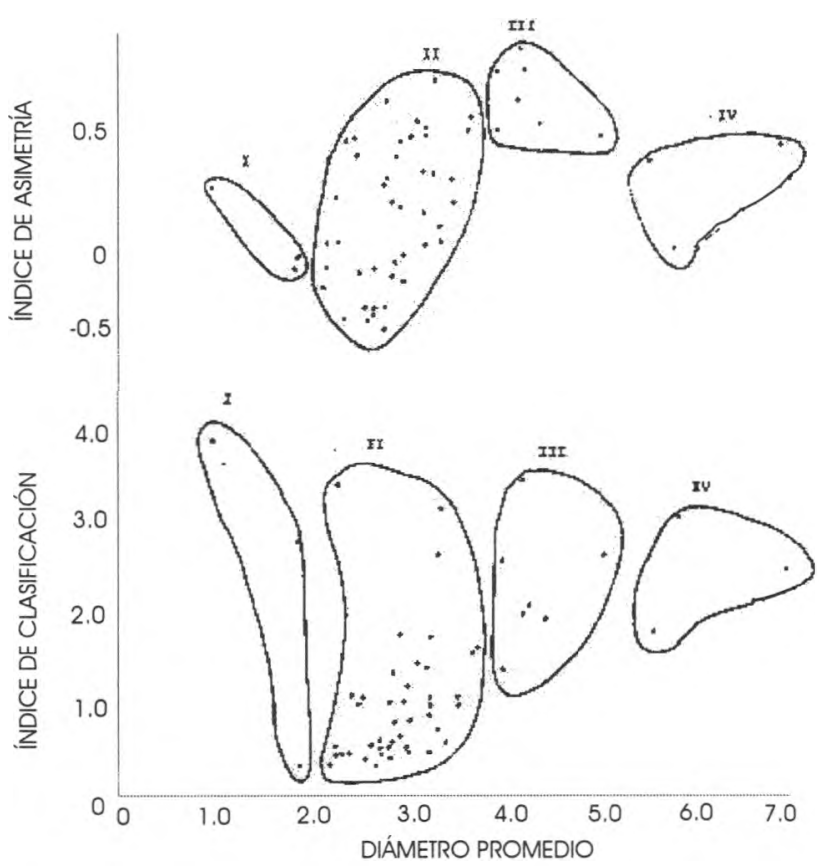

Figura 5a. Bahias San Ignacio, Navachiste y plataforma continental interna. Octubre de 1991.

Grupos texturales, propuestos resultantes de la correlación del diámetro promedio con los indices de clasificación y asimetria, según el método de Inman (1952) 
Tabla 2. Resultados granulométricos de las bahías San Ignacio, Navachiste y la plataforma continental interna adyacente del muestreo efectuado en octubre de 1991

\begin{tabular}{|c|c|c|c|c|c|c|c|c|c|c|c|c|c|}
\hline & No. de estación & $\%$ Grava & $\%$ Arena & $\%$ Limo & $\%$ Arcilla & $\mathrm{MZ}$ & Caracterización & SI & Clasificado & SKI & Asimetría & $\%$ Carbonatos & \% Carbono org. \\
\hline $\mathrm{s}$ & 1 & 0.00 & 100.00 & 0.00 & 0.00 & 1.84 & Arena media & 0.35 & Muy bien & -0.17 & Negativa & 7.11 & 0.1209 \\
\hline A & 2 & 0.00 & 100.00 & 0.00 & 0.00 & 2.26 & Arena fina & 0.41 & Bien & -0.06 & Casi simétrica & 10.65 & 0.1285 \\
\hline \multirow[t]{2}{*}{$\mathrm{N}$} & 3 & 0.00 & 100.00 & 0.00 & 0.00 & 2.39 & Arena fina & 0.4 & Bien & -0.39 & Negativa & 4.49 & 0.1405 \\
\hline & 4 & 0.00 & 100.00 & 0.00 & 0.00 & 2.62 & Arena fina & 0.33 & Muy bien & -0.39 & Negativa & 4.01 & 0.1285 \\
\hline I & 5 & 0.00 & 67.69 & 20.57 & 11.74 & 4.22 & Limo grueso & 1.96 & Mal & 0.8 & Positiva & 3.88 & 1.1637 \\
\hline G & 6 & 0.00 & 28.22 & 56.00 & 15.78 & 4.22 & Limo grueso & 3.28 & Muy mal & 0.57 & Positiva & 21.61 & \\
\hline $\mathrm{N}$ & 7 & 0.00 & 33.88 & 37.83 & 28.29 & 5.84 & Limo medio & 2.91 & Muy mal & -0.09 & Casi simétrica & 20.54 & 2.38 \\
\hline A & 8 & 0.00 & 90.74 & 4.87 & 4.39 & 2.88 & Arena fina & 0.93 & Moderadamente & 0.32 & Casi positiva & 3.82 & 0.4005 \\
\hline C & 9 & 0.00 & 84.06 & 8.24 & 7.16 & 3.12 & Arena muy fina & 1.38 & Mal & 0.41 & Casi positiva & 4.16 & 0.4836 \\
\hline I & 10 & 0.00 & 72.59 & 18.18 & 9.23 & 3.38 & Arena muy fina & 2.48 & Muy mal & 0.66 & Positiva & 15.54 & 0.6423 \\
\hline \multirow[t]{8}{*}{0} & 11 & 0.00 & 5.91 & 67.83 & 26.26 & 7.03 & Limo muy fino & 2.39 & Muy mal & 0.36 & Positiva & 4.59 & 2.865 \\
\hline & 12 & 0.00 & 91.32 & 5.69 & 2.98 & 2.52 & Arena fina & 1.06 & Mal & 0.34 & Positiva & 5.51 & 0.4156 \\
\hline & 13 & 0.00 & 93.33 & 4.51 & 2.16 & 2.86 & Arena fina & 0.77 & Moderadamente & 0.13 & Positiva & 9.3 & 0.0075 \\
\hline & 15 & 15.21 & 57.04 & 19.82 & 7.57 & 2.29 & Arena fina & 3.28 & Muy mal & 0.15 & Positiva & 55.03 & 0.135 \\
\hline & 16 & 0.00 & 45.65 & 39.27 & 15.08 & 5.11 & Limo medio & 2.55 & Muy mal & 0.41 & Positiva & 22.61 & 0.15 \\
\hline & 17 & 0.00 & 85.09 & 10.95 & 3.15 & 3.22 & Arena muy fina & 0.8 & Moderadamente & 0.26 & Positiva & 6.39 & \\
\hline & 18 & 0.00 & 86.99 & 8.25 & 4.76 & 3.26 & Arena myu fina & 1.1 & Mal & 0.44 & Positivav & 4.89 & 0.06 \\
\hline & 19 & 0.00 & 81.22 & 12.77 & 6.01 & 3.25 & Arena muy fina & 1.69 & Mal & 0.47 & Positiva & 6.64 & 0.03 \\
\hline $\mathrm{N}$ & 20 & 7.07 & 78.46 & 10.55 & 3.92 & 2.93 & Arena fina & 1.73 & Mal & -0.14 & Negativa & 18.61 & 0.045 \\
\hline A & 21 & 14.99 & 68.07 & 11.97 & 4.97 & 1.93 & Arena media & 2.76 & Muy mal & -0.12 & Negativa & 42.38 & 0.0525 \\
\hline v & 22 & 0.00 & 54.01 & 37.91 & 7.99 & 4.48 & Limo grueso & 1.83 & Mal & 0.46 & Positiva & 14.98 & 0.0975 \\
\hline A & 23 & 0.00 & 72.95 & 21.31 & 5.74 & 4.00 & Limo grueso & 1.29 & Mal & 0.68 & Positiva & 6.25 & 0.045 \\
\hline C & 24 & 10.25 & 52.13 & 29.66 & 7.95 & 3.39 & Arena muy fina & 3.14 & Muy mal & -0.06 & Casi simétrica & 48.2 & 1.0067 \\
\hline $\mathrm{H}$ & 25 & 0.00 & 93.06 & 4.59 & 2.35 & 3.01 & Arena muy fina & 0.77 & Moderadamente & -0.12 & Negativa & 12.97 & 0.2793 \\
\hline I & 26 & 0.00 & 75.77 & 19.52 & 4.71 & 3.72 & Arena muy fina & 1.56 & Mal & 0.48 & Positiva & 8.81 & 0.4248 \\
\hline$S$ & 27 & 0.00 & 98.83 & 0.36 & 0.81 & 2.70 & Arena fina & 0.47 & Bien & -0.17 & Negativa & 3.14 & \\
\hline $\mathrm{T}$ & 28 & 0.00 & 91.83 & 4.58 & 3.59 & 2.82 & Arena fina & 0.96 & Moderadamente & 0.22 & Positiva & 5.27 & 0.403 \\
\hline \multirow[t]{11}{*}{ E } & 29 & 0.00 & 94.47 & 3.95 & 1.58 & 2.84 & Arena fina & 0.55 & Moderadamente & 0.19 & Positiva & 4.77 & 1.188 \\
\hline & 30 & 39.97 & 37.07 & 17.71 & 4.52 & 0.94 & Arena gruesa & 3.82 & Muy mal & 0.19 & Positiva & 94.54 & 1.326 \\
\hline & 31 & 0.00 & 91.91 & 7.47 & 0.62 & 3.41 & Arena muy fina & 0.52 & Moderadamente & 0.01 & Casi simétrica & 10.38 & 0.192 \\
\hline & 32 & 0.00 & 100.00 & 0.00 & 0.00 & 2.81 & Arena fina & 0.37 & Bien & -0.34 & Nrgativa & 4.84 & 0.061 \\
\hline & $18 \mathrm{~A}$ & 0.00 & 61.91 & 26.13 & 11.96 & 4.06 & Limo grueso & 2.45 & Muy mal & 0.43 & Positiva & 5.67 & 0.717 \\
\hline & $25 \mathrm{~A}$ & 0.00 & 13.74 & 74.68 & 11.58 & 5.58 & Limo medio & 1.7 & Mal & 0.3 & Positiva & 12.65 & 1.0975 \\
\hline & $29 \mathrm{~A}$ & 0.00 & 84.68 & 7.22 & 8.09 & 3.21 & Arena muy fina & 1.32 & Mal & 0.49 & Positiva & 6.27 & 0.3951 \\
\hline & 33 & 0.00 & 100.00 & 0.00 & 0.00 & 2.15 & Arena fina & 0.29 & Muy bien & -0.26 & Negativa & 2.5 & 0.0962 \\
\hline & 34 & 0.00 & 96.44 & 3.00 & 0.56 & 2.93 & Arena fina & 0.42 & Bien & 0.1 & Positiva & 3.43 & \\
\hline & 35 & 0.00 & 56.86 & 34.97 & 8.17 & 4.31 & Limo grueso & 2.09 & Muy mal & 0.7 & Positiva & 4.21 & 0.222 \\
\hline & 36 & 0.00 & 78.69 & 20.29 & 1.02 & 3.54 & Arena muy fina & 1.04 & Mal & 0.12 & Positiva & 7.69 & 0.348 \\
\hline $\mathrm{P}$ & $36 \mathrm{~A}$ & 0.00 & 97.78 & 0.29 & 1.93 & 2.72 & Arena fina & 0.43 & Bien & -0.35 & Negativa & 6.9 & 0.2511 \\
\hline $\mathrm{L}$ & 37 & 0.00 & 84.56 & 14.80 & 0.64 & 3.25 & Arena muy fina & 0.94 & Moderadamente & -0.07 & Casi simétrica & 7.66 & 0.377 \\
\hline A. & 38 & 0.00 & 79.79 & 18.34 & 1.87 & 3.58 & Arena muy fina & 0.94 & Moderadamente & 0.22 & Positiva & 6.72 & 0.4047 \\
\hline $\mathrm{T}$ & 42 & 0.00 & 100.00 & 0.00 & 0.00 & 2.57 & Arena fina & 0.35 & Bien & -0.19 & Negativa & 5.58 & 0.2 \\
\hline A & 43 & 0.00 & 100.00 & 0.00 & 0.00 & 2.60 & Arena fina & 0.47 & Bien & -0.34 & Negativa & 5.42 & 0.1629 \\
\hline $\mathrm{F}$ & 44 & 0.00 & 100.00 & 0.00 & 0.00 & 2.81 & Arena fina & 0.56 & Moderadamente & -0.45 & Negativa & 6.04 & 0.318 \\
\hline 0 & $44 \mathrm{~A}$ & 0.00 & 90.34 & 4.43 & 5.23 & 3.05 & Arena muy fina & 1.17 & Mal & 0.39 & Negativa & 5.26 & 0.3365 \\
\hline $\mathrm{R}$ & 45 & 0.00 & 97.64 & 2.22 & 0.14 & 3.07 & Arena muy fina & 0.44 & Bien & -0.23 & Negativa & 6.11 & 0.318 \\
\hline M & 46 & 0.00 & 97.60 & 2.22 & 0.18 & 2.87 & Arena fina & 0.6 & Moderadamente & -0.21 & Negativa & 7.92 & 0.363 \\
\hline \multirow[t]{9}{*}{ A } & 47 & 0.00 & 98.70 & 1.03 & 0.27 & 2.70 & Arena fina & 0.52 & Moderadamente & .0 .37 & Negativa & 6.99 & 0.3939 \\
\hline & 48 & 0.00 & 88.47 & 10.48 & 1.05 & 3.33 & Arena muy fina & 0.64 & Moderadamente & 0.25 & Positiva & 7.53 & 0.5454 \\
\hline & 49 & 0.00 & 92.14 & 6.01 & 1.85 & 3.24 & Arena muy fina & 0.41 & Bien & 0.07 & Casi simétrica & 5.9 & 0.4696 \\
\hline & $49 \mathrm{~A}$ & 0.00 & 65.73 & 28.03 & 6.23 & 3.74 & Arena muy fina & 1.57 & Mal & 0.5 & Positiva & 5.21 & 0.3951 \\
\hline & $58 \mathrm{~A}$ & 0.00 & 89.08 & 8.11 & 2.81 & 2.51 & Arena fina & 0.96 & Moderadamente & 0.4 & Positiva & 7.34 & \\
\hline & $60 \mathrm{~A}$ & 0.00 & 82.48 & 14.00 & 3.52 & 2.85 & Arena fina & 1.27 & Mal & 0.53 & Positivav & 6.59 & \\
\hline & $62 \mathrm{~A}$ & 0.00 & 95.94 & 1.04 & 3.02 & 2.22 & Arena fina & 0.4 & Bien & -0.18 & Negativa & 4.85 & \\
\hline & $71 \mathrm{~A}$ & 0.00 & 95.62 & 2.86 & 1.52 & 2.19 & Arena fina & 0.49 & Bien & .0 .06 & Casi simétrica & 7.35 & \\
\hline & $74 \mathrm{~A}$ & 0.00 & 87.10 & 10.53 & 2.37 & 2.41 & Arena fina & 1.1 & $\mathrm{Mal}$ & 0.39 & Positiva & 4.5 & \\
\hline
\end{tabular}


Grupo I. Corresponde al 5\% de los sedimentos, el cual está representado por arena de tamaño promedio $\mathrm{Mz}$ de 0.94 a $1.93 \varphi$, muy bien clasificada a muy mal clasificada, con un valor del índice de 0.35 a $3.82 \varphi$, con una asimetría hacia los tamaños finos y asimétricos hacia los tamaños gruesos, con valores 0.19 a $0.17 \varphi$.

Grupo II. Comprende el $78 \%$ de los sedimentos analizados y lo constituyen las arenas de grano fino a muy fino con Mz comprendido entre los valores 2.15 a $3.74 \varphi$, muy bien clasificados, Jo de 0.29 a $3.28 \varphi$; muy asimétricos hacia los tamaños finos, a muy asimétricos hacia los tamaños gruesos (Ski: 0.66 a $0.45 \varphi$ ) a excepción de la muestra 31 que es casi simétrica Ski: $0.01 \varphi$ ); el porcentaje restante corresponde a los grupos texturales de las arenas limosas, limos arenosos, limos arcillosos y arena limo arcillosa.

Grupo III. Abarca el $12 \%$ de la población analizada, se trata de limos gruesos a medios, con tamaño medio $\mathrm{Mz}$, que varía de 4.0 a $5.11 \varphi$; mal clasificados a muy mal clasificados, Jo de 1.29 a $3.28 \varphi$; muy asimétricos hacia los tamaños finos.

Grupo IV. Incluye al $5 \%$ de los sedimentos analizados, formado por limo medio a limo muy fino, $\mathrm{Mz}$ de 5.58 a $7.03 \varphi$; bien clasificado, Jo: 1.70 a $2.91 \varphi$; casi simétrico o con ligera asimetría negativa (Ski: $-0.09 \varphi)$, a muy asimétrico hacia los tamaños finos (Ski: 0.30 a $0.36 \varphi$ ), representados por limo arenoso, limo arcilloso y arena limo arcillosa.

El grupo predominante es de arenas finas a muy finas, su distribución es amplia y comprende casi la totalidad del fondo de las bahías y de la plataforma, salvo algunas áreas que contienen sedimentos de textura diferente. Asimismo, es el material formador de las playas y de los frecuentes flechas y barras. Se identificó en las dunas, tanto actuales como antiguas y en los cordones litorales (Fig. 5b).

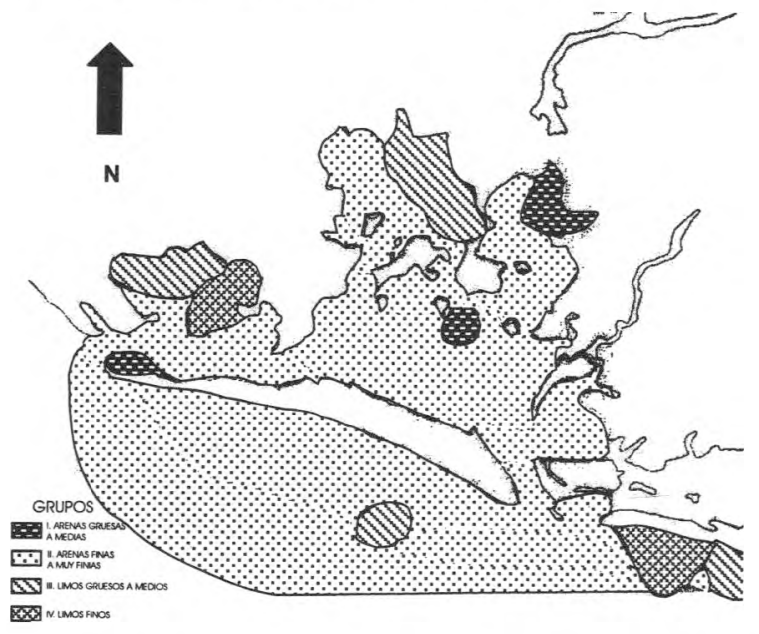

Figura 5b. Bahias San Ignacio, Navachiste y plataforma continental interna. Octubre de 1991.

Mapa de distribución de los grupos texturales determinados de acuerdo al criterio de Inman y Chamberlain (1995), (Vergara et al.,1991)
Otro grupo importante es el de las arenas limosas, dispuestas, en mucho menor proporción que el grupo anterior, dentro de la bahía Terome; en toda la parte norte de la bahía Navachiste a excepción de la muestra 30 , que presenta un lente de material limo arenoso hacia la parte noreste de esta bahía; y en la plataforma forma un parche al suroeste de la boca Vasiquilla y frente a la parte media de la Isla Macapule, representado por la muestra $18 \mathrm{~A}$.

Al grupo limo arenoso, dispuesto en varios pequeños parches, se le identificó al norte dentro de la bahía San Ignacio, al noroeste de la bahía Navachiste y en la plataforma al sureste de la boca Vasiquilla. Los sedimentos limo arcillosos fueron muy escasos, únicamente se encontraron al noreste de la bahía San Ignacio.

La fracción inorgánica de las arenas en las bahías y en la plataforma es cuarzo-feldespática, con porcentajes comprendidos entre 65 y $84 \%$ de cuarzo y de 1 a $12 \%$ de feldespatos dentro de la bahía San Ignacio. En la bahía Navachiste se registran los siguientes porcentajes: 60 a $87 \%$ de cuarzo y de 0 a $15 \%$ de feldespatos. Los sedimentos de la plataforma continental indican valores de 55 a $87 \%$ de cuarzo y de 0 a $21 \%$ de feldespatos; los porcentajes de fragmentos de roca oscilan entre 1 y $22 \%$ para toda el área; los porcentajes de minerales oscuros varían de 0 a $12 \%$, con una mayor concentración dentro de las bahías; el porcentaje de otros minerales oscila entre 2 y $12 \%$ (Tabla 3 ).

Tabla 3. Resultados del análisis composicional de las bahías San Ignacio, Navachiste y la plataforma continental interna adyacente del muestreo efectuado en octubre de 1991

\begin{tabular}{|c|c|c|c|c|c|c|}
\hline & No. de estación & $\% \mathrm{QZO}$ & $\%$ Feld. & $\%$ Roca & $\%$ Opacos & $\%$ Otros \\
\hline $\mathrm{S}$ & 1 & 72.29 & 6.78 & 9.69 & 5.23 & 6.01 \\
\hline A & 2 & 84.94 & 0.96 & 5.98 & 4.06 & 4.06 \\
\hline \multirow[t]{2}{*}{$\mathrm{N}$} & 3 & 65.80 & 10.80 & 3.40 & 12.60 & 7.40 \\
\hline & 4 & 81.20 & 9.20 & 1.20 & 3.20 & 5.20 \\
\hline I & 5 & & & & & \\
\hline G & 6 & 70.36 & 6.65 & 11.89 & 4.03 & 7.07 \\
\hline $\mathrm{N}$ & 7 & 80.62 & 3.68 & 8.14 & 4.46 & 3.10 \\
\hline A & 8 & 76.58 & 10.36 & 9.98 & 1.15 & 1.93 \\
\hline $\mathrm{C}$ & 9 & 77.40 & 12.20 & 3.20 & 2.80 & 4.40 \\
\hline I & 10 & 66.82 & 11.75 & 4.61 & 3.92 & 12.90 \\
\hline \multirow[t]{2}{*}{$\mathrm{O}$} & 11 & 65.03 & 6.96 & 22.25 & 2.88 & 2.88 \\
\hline & 12 & 76.71 & 1.62 & 16.97 & 1.81 & 2.89 \\
\hline $\mathrm{N}$ & 13 & 69.73 & 10.87 & 8.86 & 3.51 & 7.03 \\
\hline A & 15 & 87.03 & 3.79 & 4.99 & 1.80 & 2.39 \\
\hline V & 16 & 81.03 & 1.73 & 7.66 & 5.55 & 4.03 \\
\hline A & 17 & 74.20 & 5.38 & 13.62 & 2.60 & 4.20 \\
\hline $\mathrm{C}$ & 18 & 59.07 & 15.33 & 14.63 & 2.09 & 8.88 \\
\hline $\mathrm{H}$ & 19 & 80.77 & 8.85 & 1.92 & 2.88 & 5.58 \\
\hline I & 20 & 71.87 & 10.16 & 13.09 & 0.98 & 3.90 \\
\hline $\mathrm{S}$ & 21 & 79.92 & 6.95 & 3.09 & 5.60 & 4.44 \\
\hline $\mathrm{T}$ & 22 & 69.00 & 7.60 & 7.80 & 5.60 & 10.00 \\
\hline $\mathrm{E}$ & 23 & 76.34 & 9.94 & 4.78 & 2.58 & 6.36 \\
\hline
\end{tabular}


DOI: http://dx.doi.org/10.22201/fi.25940732e.2001.02n1.002

\begin{tabular}{|c|c|c|c|c|c|c|}
\hline & No. de estación & $\%$ QZO & $\%$ Feld. & $\%$ Roca & $\%$ Opacos & $\%$ Otros \\
\hline $\mathrm{N}$ & 24 & 76.54 & 9.81 & 1.35 & 1.15 & 11.15 \\
\hline A & 25 & 72.65 & 0.00 & 4.70 & 11.41 & 11.24 \\
\hline V & 26 & 71.98 & 7.00 & 14.39 & 1.56 & 5.07 \\
\hline A & 27 & 82.40 & 5.60 & 0.60 & 5.80 & 5.60 \\
\hline $\mathrm{C}$ & 28 & 77.16 & 10.64 & 7.09 & 0.98 & 4.13 \\
\hline $\mathrm{H}$ & 29 & 76.04 & 4.37 & 15.21 & 1.53 & 2.85 \\
\hline I & 30 & 67.00 & 10.80 & 3.40 & 6.00 & 12.80 \\
\hline S & 31 & 72.00 & 12.00 & 6.00 & 6.40 & 3.60 \\
\hline$T$ & 32 & 77.00 & 3.60 & 10.40 & 2.20 & 6.80 \\
\hline \multirow[t]{7}{*}{$\mathrm{E}$} & $18 \mathrm{~A}$ & 64.40 & 13.00 & 5.60 & 4.20 & 12.80 \\
\hline & $25 \mathrm{~A}$ & 75.00 & 0.60 & 13.80 & 4.80 & 5.80 \\
\hline & $29 \mathrm{~A}$ & 69.67 & 7.67 & 13.80 & 3.24 & 5.62 \\
\hline & 33 & & & & & \\
\hline & 34 & 73.00 & 4.20 & 15.00 & 1.00 & 6.80 \\
\hline & 35 & 76.60 & 10.20 & 8.80 & 2.60 & 1.80 \\
\hline & 36 & 77.20 & 11.40 & 1.60 & 4.20 & 5.60 \\
\hline $\mathrm{P}$ & $36 \mathrm{~A}$ & 54.80 & 21.00 & 8.60 & 9.60 & 6.00 \\
\hline $\mathrm{L}$ & 37 & 74.35 & 6.96 & 9.34 & 3.58 & 5.77 \\
\hline A & 38 & 77.20 & 3.00 & 9.20 & 3.40 & 7.20 \\
\hline $\mathrm{T}$ & 42 & 80.40 & 0.60 & 10.20 & 3.00 & 5.80 \\
\hline A & 43 & 83.00 & 3.00 & 9.00 & 1.60 & 3.40 \\
\hline $\mathrm{F}$ & 44 & 73.00 & 6.80 & 1.40 & 9.20 & 9.60 \\
\hline O & $44 \mathrm{~A}$ & 72.80 & 5.80 & 13.60 & 2.20 & 5.60 \\
\hline $\mathrm{R}$ & 45 & 75.60 & 7.60 & 3.80 & 6.20 & 6.80 \\
\hline $\mathrm{M}$ & 46 & 87.60 & 3.00 & 3.60 & 1.80 & 4.00 \\
\hline \multirow[t]{9}{*}{ A } & 47 & 84.40 & 3.00 & 7.00 & 1.20 & 4.40 \\
\hline & 48 & & & & & \\
\hline & 49 & 76.20 & 8.00 & 8.20 & 1.60 & 6.00 \\
\hline & $49 \mathrm{~A}$ & 82.60 & 7.00 & 1.40 & 2.40 & 6.60 \\
\hline & $58 \mathrm{~A}$ & 82.40 & 9.00 & 1.80 & 2.20 & 4.60 \\
\hline & $60 \mathrm{~A}$ & 83.20 & 0.40 & 12.60 & 1.60 & 2.20 \\
\hline & $62 \mathrm{~A}$ & 82.65 & 0.00 & 11.28 & 1.30 & 4.77 \\
\hline & $71 \mathrm{~A}$ & 56.40 & 15.60 & 22.60 & 1.80 & 3.60 \\
\hline & $74 \mathrm{~A}$ & 87.60 & 0.00 & 0.20 & 0.20 & 12.00 \\
\hline
\end{tabular}

El análisis de la fracción orgánica consistió en determinar: el porcentaje de foraminíferos, el cual varía de 0 a $50 \%$, los mayores porcentajes se obtuvieron en las muestras 8,16 , 22,23 y 31 con valores mayores de $22 \%$ y excepcionalmente en las muestras 24 y $25 \mathrm{~A}$ con valores de 40 y $50 \%$, respectivamente; las conchas enteras de moluscos con porcentajes de 0 a $16 \%$, se localizaron prácticamente en toda la zona, a excepción de la estación 11, en la cual no se encontraron organismos; las conchas fracturadas de moluscos presentaron mayores porcentajes que las anteriores, los cuales oscilan entre 0 y $90 \%$; y otra fracción orgánica en la cual se incluyeron espículas y fibras vegetales, representan porcentajes pequeños que varían de 0 a $20 \%$, en los cuales, las fibras vegetales fueron casi nulas.

El contenido porcentual de carbonatos totales en los sedimentos superficiales varió entre 12 y $94 \%$, con la mayoría de valores entre 4 y $20 \%$, los mayores porcentajes se presentan dentro de la bahía Navachiste en las estaciones 15 y 30 con valores de 55 a 94\%, respectivamente. Los valores menores de 2 a $7 \%$, corresponden a la plataforma. Las concentraciones altas de carbonatos (más de $40 \%$ ) se obtuvieron en los sedimentos recuperados dentro de las bahías, caracterizados por el importante contenido de conchas de moluscos (Fig. 6a).

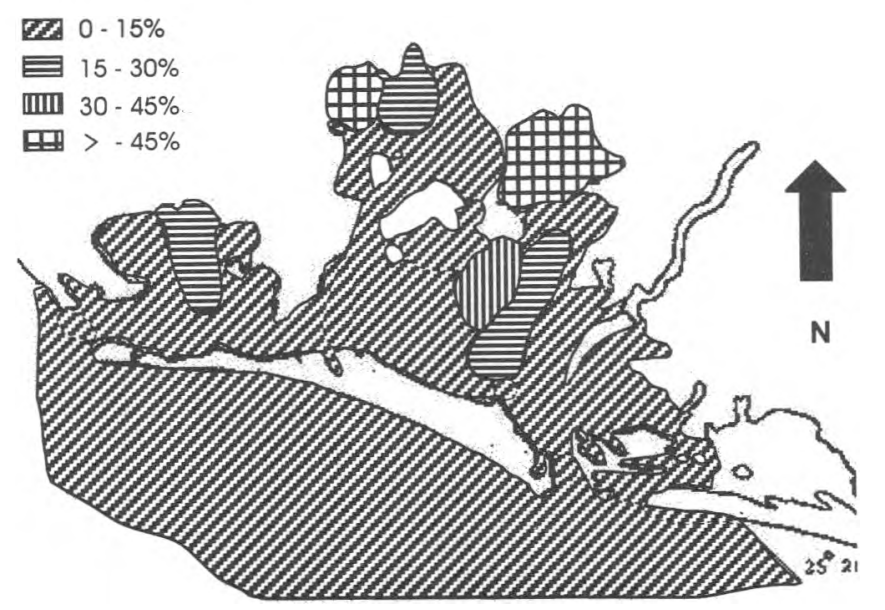

Figura 6a. Bahias San Ignacio, Navachiste y plataforma continental interna. Octubre de 1991. Contenido porcentual de carbonatos (Vergara et al., 1991)

El contenido de carbono orgánico es más elevado en la parte este de la bahía San Ignacio con valores de 2.38 y $2.86 \%$. La bahía Navachiste muestra un contenido homogéneo, con valores menores de $1 \%$, a excepción de las muestras obtenidas de las estaciones 24,29 y 30 las cuales presentaron valores de $1.00,1.18$ y $1.32 \%$, respectivamente.

La plataforma continental adyacente presenta valores de carbono orgánico en casi toda la zona, excepto en la parte sureste de la boca Vasiquilla donde se detectaron valores más altos, los cuales corresponden a la estación 25 a (1.09\%) (Fig. 6b).

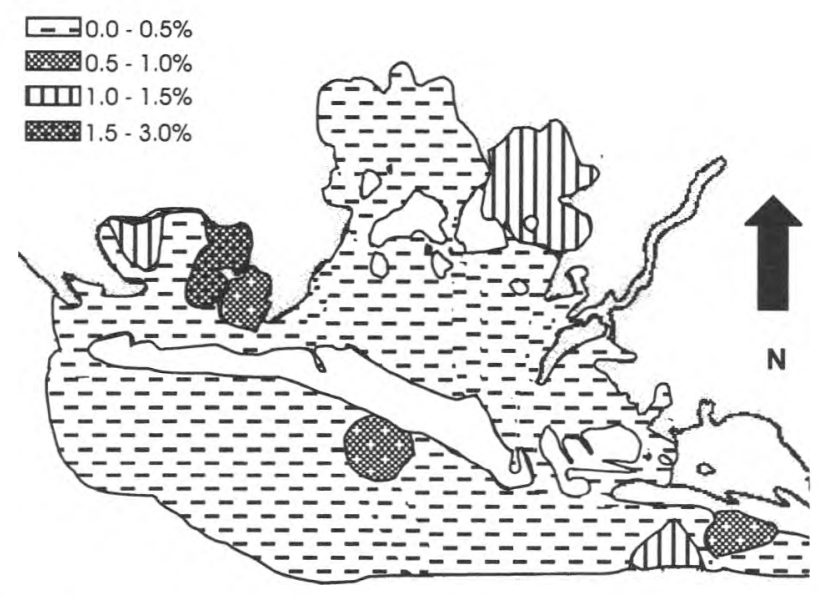

Figura 6b. Bahias San Ignacio, Navachiste y plataforma continental interna. Octubre de 1991. Contenido porcentual de materia orgánica (Vergara et al., 1991) 
El color de los sedimentos varió de café grisáceo a café amarillento frente a las islas San Ignacio y Vinorama en el golfo de California y en la costa oeste de la bahía San Ignacio; de negro oliva a negro verdoso en el interior de las bahías San Ignacio y Navachiste y en la costa sur de la isla Macapule fue gris oscuro al noreste de la bahía Navachiste y al sur de la isla San Ignacio (Fig. 7).

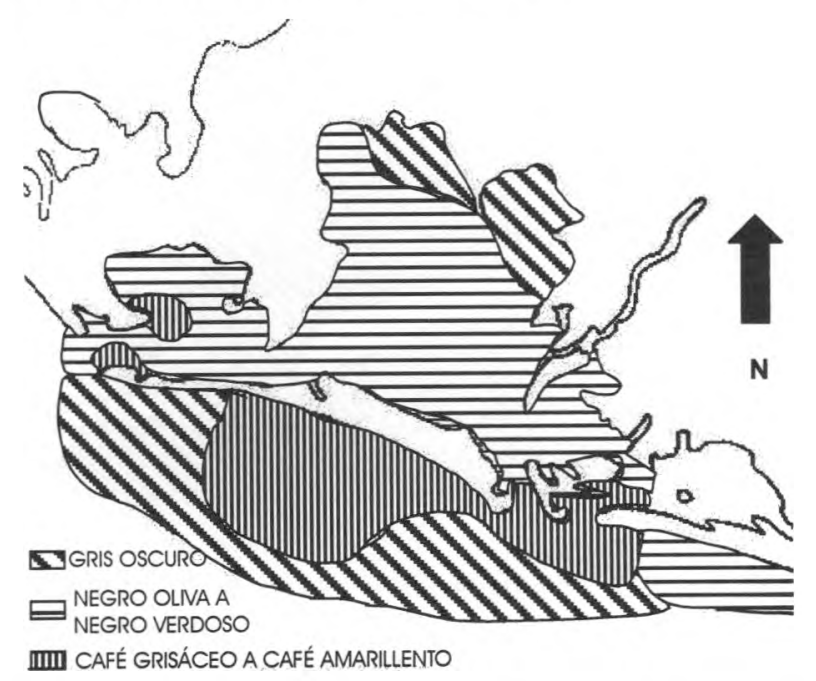

\begin{abstract}
Figura 7. Bahias San Ignacio, Navachiste y plataforma continental interna. Octubre de 1991. Distribución de color del sedimento (Vegara et al., 1991)
\end{abstract}

\section{Discusión}

Las bahías San Ignacio y Navachiste se alojan en una depresión marginal costera intradeltáica y consisten en dos cuencas someras intercomunicadas entre sí, que forman un sistema lagunar relacionado con los procesos sedimentarios, los cuales han favorecido el desarrollo de las llanuras aluviales de los ríos Fuerte y Sinaloa considerados en una etapa de madurez temprana en las partes superior y media de sus cauces, mientras que en su porción inferior dentro de la llanura costera, presentan una etapa de madurez tardía (Rodríguez y Cordova, 1978).

Cada cuenca tiene rasgos físicos distintivos que la caracterizan e individualizan, debido principalmente a la morfología, fisiografía litoral y actividad hidrodinámica existente en la zona.

La distribución sedimentaria en las bahías y en la plataforma está caracterizada por arenas de diferentes tamaños con el predominio de arenas finas a muy finas, con una clasificación ( tiva, bajo contenido de carbonatos $(2.50$ a $94.54 \%)$ y carbono orgánico $(0.0075$ a $2.865 \%)$, en un aspecto general. $\mathrm{Al}$ respecto, la distribución granulométrica resultó muy similar a la obtenida por Phleger y Ayala-Castañares (1969) y Muhech-Jallat (1990). Entre otros rasgos importantes se pueden señalar, la presencia de limos de diversos tamaños en el área de estudio de la parte interior de las bahías San Ignacio y Navachiste, así como en sedimentos de la plataforma, ubicados al sur de la isla Macapule; coincidiendo en estas áreas con los porcentajes más altos del contenido de carbonatos y de carbón orgánico. De igual manera, los sedimentos muy bien clasificados a bien clasificados con un color de sedimento de café oscuro a negro grisáceo se detectaron en zonas donde se tiene más energía, como es el caso de los sedimentos que se ubican en las inmediaciones de las bocas de acceso a las bahías y de aquellos que se encuentran dentro de los canales naturales originados por el flujo y reflujo de las mareas.

El marco sedimentológico anterior, permite analizar el comportamiento sedimentario presente en el área de estudio, apoyado en la fisiografía litoral, morfología, presencia de canales naturales y en el conocimiento de los vertimientos de aguas residuales, sin olvidar el sistema de corrientes y mareas presentes en el área.

Las bahías San Ignacio y Navachiste, tienen condiciones similares en cuanto a la distribución sedimentaria, manifestándose por el predominio de arenas finas muy bien clasificadas en la entrada de las bocas de las bahías, esto se debe a que en estas áreas existe una mayor velocidad de las corrientes, lo cual trae consigo una mejor selección de las partículas sedimentarias; de igual manera, este grado de clasificación se manifiesta en sedimentos ubicados en los canales naturales; no así, hacia las partes más internas, en las cuales se presenta una disminución de la velocidad de las corrientes al depositarse limos con una mala clasificación, debido al aporte simultáneo de material grueso que está siendo cubierto por material fino al encontrar condi. ciones propicias de depósito.

La depositación de la materia orgánica se localiza asociada con limos y arcillas debido a la adherencia a dicho material y la descarga de aguas negras y aguas residuales para riego, esta asociación la señalan Méndez et al., (1986), al estudiar aspectos ecológicos en la contaminación del hábitat de los organismos macrobentónicos. Sin embargo, existen otros factores determinantes que condicionan el contenido orgánico de los sedimentos, como son la deposición y descomposición orgánica.

La asociación de las partículas finas con el contenido de materia orgánica se debe a que al depositarse las partículas finas en ausencia de corrientes, el agua permanece casi estancada, provocando la proliferación de bacterias que consumen el oxígeno del agua y por lo tanto cambian el Eh de positivo a negativo, el ambiente se vuelve "reductor", y propicia el desarrollo de la materia orgánica.

Los patrones de transporte de los sedimentos, tomando en cuenta la disminución del tamaño promedio de las partículas, muestran una circulación preferencial hacia las 
partes más internas de las bahías San Ignacio y Navachiste, teniendo una mejor gradación la bahía San Ignacio; asimismo, ésta circulación se manifiesta de oeste a este sobre la plataforma. Esta circulación preferencial en ambos casos es debida al transporte de las partículas, que viajan por tracción y saltación y en menor medida, por suspensión hacia las zonas más internas de las bahías; y en el caso de la plataforma, la circulación se debe a las corrientes de litoral ocasionadas por el oleaje que al incidir en un cierto ángulo sobre la costa originan dichas corrientes. Como en el caso de la región de Yavaros, Sonora, donde Ayala et al., (1980), reportan que el ángulo de incidencia del oleaje es de 0 a $30^{\circ}$ y la dirección de la corriente hacia el este presenta velocidades de 3.9 a $20 \mathrm{~cm} / \mathrm{seg}$.

La geología regional y la fisiografía del área, son el resultado de la tectónica de placas y de los cambios del nivel del mar.

La costa sinaloense, presenta relieve abrupto y llanuras inclinadas hacia el océano, en las cuales están presentes antiguas líneas de costa que evidencian el carácter progradante de la región y confieren a la fisiografía litoral, características similares a las descritas por Curray y Moore (1963), Curray et al,. (1969), Bird (1969) y Snead (1982).

Respecto a la morfología costera que presenta el área, los rasgos más sobresalientes son: antiguas líneas de playa, antiguas llanuras de inundación fluvial, dunas activas y dunas estabilizadas. Evidencias de este tipo se pueden encontrar desde la desembocadura del río Fuerte hasta San Blas Nayarit, en donde la llanura costera consiste principalmente de antiguas líneas de costa y que según Curray (1961), se puede clasificar como una regresión deposicional; estas crestas se forman como una barra sumergida a lo largo de la costa, con una alta proporción de arena y baja energía del oleaje; si estas condiciones prevalecen durante varios ciclos de marea, la barra se transforma en una playa quedando aislada la anterior. Lo expuesto anteriormente se puede observar en el sistema de bermas de la isla San Ignacio.

Aún es incierta la edad de las antiguas líneas de playa y el desarrollo de la llanura costera que en el estado de Nayarit, llega a tener hasta $17 \mathrm{~km}$ de amplitud; el fechado con $\mathrm{C}^{14}$ sugiere que el nivel del mar alcanzó su posición actual hace aproximadamente 3000 a 5000 años (Curray y Moore, 1963; Curray et al., 1969). Con base en evidencias geológicas en el golfo de California, Curray (1961) y Phleger (1969), indican que el actual nivel del mar se alcanzó hace unos 2000 a 2500 años.

Los rasgos fisiográficos identificados en el área de estudio, pueden ser considerados como remanentes de antiguas formaciones costeras, originadas durante la glaciación wisconsiniana o la regresión holocénica, que según Curray et al., (1969), continúa actualmente, aunque más lenta, debido a los cambios climáticos y a la acumula. ción de lodos terrígenos sobre las arenas transgresivas de la plataforma.

En la zona costera del área de estudio, no se observan deltas; no obstante, existen dunas activas bien desarrolladas en las islas San Ignacio y Macapule; asimismo, se tiene un buen desarrollo de barreras litorales en forma de flechas, tómbolos y playas en la mayor parte del área, lo que denota que existe un gran aporte de sedimentos por la acción de las corrientes marinas. Se observa la dirección preferencial de las corrientes de oeste a este, aunque la existencia de otras direcciones locales se manifesta por la presencia de pequeñas islas de arena, localizadas al noroeste de punta San Ignacio y en la boca de acceso a la bahía San Ignacio, así como por la formación de bajos arenosos en toda la porción sur de la isla San Ignacio.

En cuanto a los sedimentos de las bahías San Ignacio y Navachiste y de la plataforma continental, la mayoría son terrígenos. La fuente de procedencia son las rocas metamórficas del Paleozoico y Mesozoico, así como las rocas ígneas intrusivas y extrusivas del Cenozoico y Cuaternario y los sedimentos del Cuaternario de la llanura costera (Carta Geológica de la República Mexicana, 1976), transportados hacia la cuenca de depósito principalmente por los ríos Fuerte y Sinaloa.

\section{Conclusiones}

1) Se determinaron cuatro grupos texturales, con base en la correlación de parámetros granulométricos esta. dísticos de los sedimentos; el más representativo es el grupo de arenas, el cual comprende $78 \%$ del material analizado y se encuentra distribuído ampliamente en la plata. forma y en el sustrato de la zona de bahías; asimismo, presenta una mejor clasificación en los canales naturales.

2) Los principales rasgos fisiográficos presentes en el área son: antiguos cordones de playa, antiguas llanuras de inundación fluvial, dunas activas y dunas estabilizadas, barreras litorales, tómbolos, flechas y playas, los cuales atestiguan la progradación por acumulación sedimentaria sin cambio del nivel del mar en la zona.

3) Los sedimentos en el sistema de bahías son principalmente terrígenos, la fuente de procedencia son rocas ígneas intrusivas y extrusivas del Cenozoico y Cuaternario y los sedimentos cuaternarios de la llanura costera, por lo tanto, se considera que el aporte de éstos se efectuó durante la divagación del río Sinaloa hacia el sureste, al formar su llanura aluvial; asimismo, formó un delta que se encuentra actualmente varios kilómetros tierra adentro.

4) El transporte sedimentario sobre la plataforma es evidente por la disminución del tamaño de grano de las 
partículas sedimentarias de oeste a este y los rasgos fisiográficos, cordón de dunas activas, antiguos cordones de playa, barras y flechas presentes en la isla San Ignacio. La granulometría dentro de las bahías presenta una distribución gradual de arenas medias y arenas finas en las bocas, a limos gruesos y limos muy finos hacia las partes más internas de las bahías, debido principalmente a la acción de las mareas y a la baja energía cinética del oleaje.

5) El contenido de carbonatos y de materia orgánica en los sedimentos, en general presenta valores bajos con porcentajes promedio de 10 y $1 \%$ respectivamente; por lo que la escase $z$ de limo, arcilla, carbonatos y materia orgánica particulada, no se considera favorecedora para el establecimiento de especies consumidoras de depósito, como los camarones del género Penaeus.

\section{Referencias}

Alba-Cornejo V., González M., Herrera M.J., LedesmaVázquez S.C., Machado-Navarro V., Rico A., RosalesContreras D.E. y Vera M.A. (1979). Estudio sedimentológico de la bahía de Puerto Viejo, Mazatlán, Sinaloa. An. Centro Ciencias del Mar y Limnol, UNAM. México. 6(1):97-101.

Ayala-Castañares A., Malpica-Cruz V.M. y Gutierrez-Estrada M. (1980). Geología marina de la región de Yavaros, Sonora, México. An. Centro Ciencias del Mar y Limnol, UNAM. México. 7 (2): 275-290.

Ayala-Castañares A., Gutierrez-Estrada M. y MalpicaCruz V.M. (1990). Morfosedimentología de la laguna de Agiabampo, Sonora. Sinaloa, México. An. Inst. Cienc. del Mar y Limnol. UNAM, 17 (2): 257-270.

Bird C.F. (1969). Coast an Introduction to Sistematic Geomorphology, Institute of Technology Press, Massachussetts. Cambridge, London, England. Vol. 4, 246 pp.

Carta geológica de la República Mexicana.(1976). Sánchez-Mejorada S. (Comp.) Esc. 1: 2000000.

Carver E.R. (1971). Procedures in Sedimentary Petrology. Wiley Interscience, New York.

Contreras-Bravo B.G. y Campos-Castán J. (1986). Programa OAGEO-1. Cálculo de los parámetros sedimentológicos. Centro de Datos e Investigaciones Oceanográficas, Dirección General de Oceanografía Naval. Secretaría de Marina.

Contreras-Bravo B.G. y Campos-Castán J. (1988). Sedimentología de la terraza continental sureste del golfo de California, México. Dirección General de Oceano. grafía Naval. Secretaría de Marina.

Contreras E.F. (1985). Las lagunas costeras mexicanas. Centro de Ecodesarrollo. Secretaría de Pesca. México.
Curray J.R. (1961). Late Quaternary sea level: a discussion. Bull Geol. Soc. America. 72 (11): 1707-1712.

Curray J.R. y Moore D.G. (1963). Sedimentos e historia de la costa de Nayarit, México. Boletín Sociedad Geológica de México. Tomo XXVI, No. 2.

Curray J.R, Emmel F.J. y Crampton P.J.S. (1969). Holocene History of a Strain Plain Lagoonal Cost. Nayarit, México. Lagunas Costeras de Ayala-Castañares A. y Phleger F.B. (Eds.). UNAM-UNESCO. Noviembre 28.30. 1967. México. 63-100.

Emery K.O. (1938). A Rapid Method of Mechanical Analysis of Sands. Jour. Sed. Pet. 105-111.

Folk R.L. (1969). Petrología de las rocas sedimentarias. Instituto de Geología, UNAM. México.

Folk R.L. y Ward W.C. (1957). Brazos River Bar: a Study in the Significance of Grain Size Parameters. Jour. Sed. Pet. 27: 3-26.

Gabriel A. y Cox E.P. (1929). A Staining Method for the Quantitative Determination of Certain Rock Mineral. Am. Mineralogist. 14: 290-292.

García E. (1973). Modificaciones al sistema de clasificación climática de Köppen. Instituto de Geografía. UNAM. México.

García-Bazán E. (1989). Materia orgánica en los sedimentos de la plataforma sureste del golfo de California, Relaciones Ecológicas y Granulométricas, Tesis Profesional ENEP. Zaragoza. 60 pp.

Grant G.M. (1971). Carbon Determination In: Procedures in Sedimentary Petrology. Carver R.E. (Ed). Wiley Interscience, Athens Georgia. 479-488.

INEGI (1984a). Carta de climas. La Paz. Clave: 12R-VIII. Esc. 1:250 000, Secretaría de Programación y Presupuesto.

INEGI (1984b). Carta geológica. Los Mochis. Clave G-12-9. Esc. 1:250 000, Secretaría de Programación y Presupuesto.

Inman D.L. (1952). Measures for Describing The size Distribution of Sediments. J. Sedim. Petrol. 22 (3): 125-145.

Inman D.L. y Chamberlain T.K. (1955). Particle size Distribution in Nearshore Sediments in: Finding Ancient Shorelines. Soc. Econ. Paleont. Min. Spec. Publ. (3): 106-126.

Jackson M.L. (1958). Soil Chemical Analysis Prentice. Hall Pub. Co., Englewood Cliffs. N.H. 356 p.

Krumbein W.C. (1932). The Mechanicals Analysis of Finegrained Sediments. Jour. Sedim. Petrol. 2 (3): 140-149.

Krumbein W.C. y Sloss L.L. (1969). Stratigraphy and Sedimentation. W.H. Freeman y Co.

Lankford R.R. (1977). Coastal Lagoons of México. Their Origin and Classification in: Estuarine Processes, Wiley M. (Ed.). Academic Press. 2: 182- 215.

Lecuanda-Camacho R. (1967). Ecología y sedimentación de los manglares en las lagunas de Topolobampo, Sinaloa, México. Resultados Preliminares. Tercer Congreso Nacional de Oceanografía. Campeche, Campeche. 
López-Avilés A.R. (1986). Morfología y sedimentos superficiales de la porción meridional de la plataforma continental de Sinaloa, México. Tesis Profesional de ingeniería, Facultad de Ingeniería, UNAM.

Malpica-Cruz V., Gutiérrez-Estrada M. y L̇edezma-Guerrero O. (1975). Hoja geológica isla San Ignacio. $12 \mathrm{R}$ 1(1). Esc. 1:100 000. UNAM. Instituto de Geología. Carta Geológica de México.

Méndez-Ubach M.N., Solís-Weiss V. y Carranza-Edwards A. (1986). La importancia de la granulometría en la distribución de organismos bentónicos. Estudios de playas del estado de Veracruz, México. An. Inst. Ciencias del Mar y Limnol. UNAM. 13 (3): 45-55.

Moran-Zenteno D.J. (1984). Geología de la República Mexicana. $2^{\text {da }}$ edición del Instituto Nacional de Estadística Geográfica e Informática y Facultad de Ingeniería, UNAM. 3-30.

Muhech-Jallat E. (1990). Distribución granulométrica y contenido de carbón orgánico en sedimentos de las bahías de Ohuira, Topolobampo y Santa María, Sinaloa. México. Estación Oceanográfica de Topolobampo. Dirección General de Oceanografía Naval. Secretaría de Marina.

Muhech-Jallat E. (1991). Distribución granulométrica y contenido de carbón orgánico en los sedimentos del sistema lagunar Teacapan-Agua Brava, Sinaloa, Nayarit, México. Estación Oceanográfica de Topolobampo. Dirección General de Oceanografía Naval. Secretaría de Marina. Phleger F.P. y Ayala-Castañares A. (1969). Marine Geology of Topolobampo Lagoons. In: Mem. Simp. Int.
Lagunas Costeras UNAM-UNESCO, Nov. 28-30, 1967, México. 101-136.

Poole D.M. (1957). Size Analysis of and Sand by a Sedimentation Technique. Jour. Sed. Pet. 27: 460-468.

Rodríguez-Torres R. y Cordova D.A. (1978). Atlas geológico y evaluación geológico-minera del estado de Sinaloa. Instituto de Geología, UNAM y Secretaría del Desarrollo Económico del estado de Sinaloa. 1-702.

SARH (1975). Boletín hidrológico No. 36. Región hidrológica No. 10. Dirección de Análisis y Balance Geohidrológico.

Shackley M.L. (1975). Archeological Sediments. A Survey of Analitical Methods. Butterworth y Co. Publishers. London.

Shepard F.P. (1954). Nomenclature based on sand silt-clay ration. Jour. Sed. Pet. 24: 151-158.

Snead R.E. (1982). Coastal Landforms and Surface Features: A photographic Atlas and Glossary. Rodman E.S., Stroundsburd P. y Hutchinson Ross.

Stokes G.G. (1851). On the Effect of the Internal Friction of Fluids on the Motion of Pendulums Cambridge Pheles. Soc. Trans. 19 (2): 8-106.

Van-Andel T.H. (1964). Recent Marine Sediments of Gulf of California. Van-Andel T. y Shor G.G. (Eds.). Am. Assoc. Pet. Geol. Mem. 3: 216-310.

Walkley A. y Black I.A. (1934). An Examination of the Degthareff Method for Determining Soil Organic Matter and a Proposed Modification of the Chromic Acid Titration Method. Soil Science. 27: 29-38. 
DOI: http://dx.doi.org/10.22201/fi.25940732e.2001.02n1.002

\section{Semblanza de los autores}

María de Lourdes García-Leal. Egresada como licenciada en hidrobiología de la Universidad Autónoma Metropolitana, ha laborado en la Dirección General de Oceanografía Naval de la Secretaría de Marina, en el centro acuícola del Departamento "el hombre y su ambiente" que depende de la Universidad Autónoma Metropolitana unidad Xochimilco y en las consultoras ambientales Ecodesarrollo y Ecoplaneación consultores. Su participación en proyectos interinstitucionales con la Universidad Veracruzana y la Secretaría del Medio Ambiente, Recursos Naturales y Pesca, incluye trabajo oceanográfico relativo a bacteriología, química, sedimentología y biología a bordo del buque Onyuku en las costas de Veracruz y Tabasco. Ha trabajado en gabinete, principalmente en digitalización de costas y sitios de muestreo, cálculo de isolíneas, desarrollo de análisis gráficos y numéricos. Sus áreas de especialización comprenden oceanografía biológica, caracterización de ambientes acuáticos, manejo de zonas costeras, evaluación de impacto ambiental en ambientes acuáticos, reconocimiento de patrones, análisis, interpretación y digitalización de fotografías aéreas e imágenes de satélite, técnicas numéricas y cartográficas empleadas en estudios de ordenamiento ecológico y en la elaboración de mapas.

Silvia Margarita Ortiz-Gallarza. Graduada en biología en la UAM-Xochimilco, cursó los créditos de la maestría en biología en la Facultad de Ciencias-UNAM. Cuenta con 17 años de experiencia en el desarrollo de estudios de investigación oceanográfica y ambiental. Sus áreas de incidencia son: oceanografía biológica, contaminación marina, ecología y manejo de zonas costeras, indicadores bénticos de contaminación y evaluación de impacto ambiental, entre otras. Ha efectuado procesamiento digital, interpretación y análisis de imágenes de satélite y aplicaciones de SIG en investigación ambiental. Ha participado en 22 congresos nacionales e internacionales y en el desarrollo de 12 publicaciones. En la UNAM ha laborado en la Facultad de Ciencias y el laboratorio de invertebrados; asimismo, ha colaborado en estudios malacológicos de faunística y ecología. Recibió capacitación y actualización metodológica y de trabajo de campo en el Instituto de Biología, laboratorio de química y productividad acuática-UNAM . Ha participado en 41 cruceros y muestreos, 12 estudios y cerca de 60 informes técnicos para la Secretaría de Marina; 24 salidas de campo/muestreos, 2 estudios de ordenamiento costero para la Secretaría de Pesca y en la elaboración de 17 informes técnicos de 1994 a 2000, en el Instituto Mexicano del Petróleo, incidiendo desde las fases de trabajo de campo, laboratorio y gabinete.

Santiago Vergara-Méndez. Es ingeniero geólogo egresado de la Facultad de Ingeniería de la UNAM. Durante 1998, cursó créditos de la maestría en geología ambiental en la Escuela Superior de Ingeniería y Arquitectura, unidad Ticomán, del Instituto Politécnico Nacional. $\mathrm{Ha}$ incidido en el desarrollo de estudios que incluyen: oceanografía geológica, manejo de zonas costeras, evaluación de impacto en ambientes marinos, reconocimiento de patrones, fotointerpretación, caracterización de sitios, proceso de imágenes de satélite y sistemas de información geográfica, elaboración de cartas y mapas relativos a modelos digitales de elevación y profundidad, parámetros ambientales y rasgos fisiográficos. Participó en 2 estudios de ordenamiento costero para la Secretaría de Pesca. Cuenta con 6 años de experiencia laboral en la Dirección General de Oceanografía de la Secretaría de Marina, donde participó en cruceros y muestreos oceanográficos y detección de contaminación; colaboró en el área de geología en muestreos y análisis sedimentológicos. En las consultoras Ecoplaneación Consultores y Ecodesarrollo, participó en estudios ambientales. En el Instituto Mexicano del Petróleo colaboró durante 3 años en estudios de ordenamiento ecológico, impacto, caracterización y diagnóstico de sitios. Asistió a cursos de propósito específico relacionados con riesgo geológico y ordenamiento ecológico, así como a congresos nacionales. Ha practicado la docencia a nivel medio superior y ha dirigido algunas tesis a nivel licenciatura. 